\title{
Syn-kinematic hydration reactions, grain size reduction, and dissolution-precipitation creep in experimentally deformed plagioclase-pyroxene mixtures
}

\author{
Sina Marti ${ }^{1}$, Holger Stünitz ${ }^{2,3}$, Renée Heilbronner ${ }^{1}$, Oliver Plümper $^{4}$, and Rüdiger Kilian ${ }^{1}$ \\ ${ }^{1}$ Department of Environmental Sciences, University of Basel, Basel, Switzerland \\ ${ }^{2}$ Department of Geosciences, University of Troms $\varnothing$, Troms $\varnothing$, Norway \\ ${ }^{3}$ Institut des Sciences de la Terre d'Orléans (ISTO), Université d'Orléans, Orléans, France \\ ${ }^{4}$ Department of Earth Sciences, Utrecht University, Utrecht, the Netherlands
}

Correspondence: Sina Marti (sina.marti@ed.ac.uk)

Received: 29 April 2018 - Discussion started: 7 May 2018

Revised: 11 July 2018 - Accepted: 14 July 2018 - Published: 9 August 2018

\begin{abstract}
It is widely observed that mafic rocks are able to accommodate high strains by viscous flow. Yet, a number of questions concerning the exact nature of the involved deformation mechanisms continue to be debated. In this contribution, rock deformation experiments on four different water-added plagioclase-pyroxene mixtures are presented: (i) plagioclase(An60-70)-clinopyroxene-orthopyroxene, (ii) plagioclase(An60)-diopside, (iii) plagioclase(An60)enstatite, and (iv) plagioclase(An01)-enstatite. Samples were deformed in general shear at strain rates of $3 \times 10^{-5}$ to $3 \times 10^{-6} \mathrm{~s}^{-1}, 800^{\circ} \mathrm{C}$, and confining pressure of 1.0 or 1.5 GPa. Results indicate that dissolution-precipitation creep (DPC) and grain boundary sliding (GBS) are the dominant deformation mechanisms and operate simultaneously. Coinciding with sample deformation, syn-kinematic mineral reactions yield abundant nucleation of new grains; the resulting intense grain size reduction is considered crucial for the activity of DPC and GBS. In high strain zones dominated by plagioclase, a weak, nonrandom, and geometrically consistent crystallographic preferred orientation (CPO) is observed. Usually, a CPO is considered a consequence of dislocation creep, but the experiments presented here demonstrate that a CPO can develop during DPC and GBS. This study provides new evidence for the importance of DPC and GBS in mid-crustal shear zones within mafic rocks, which has important implications for understanding and modeling mid-crustal rheology and flow.
\end{abstract}

\section{Introduction}

Viscous deformation of crustal rocks is usually dominated either by intracrystalline deformation (dislocation creep) or by a form of diffusion creep together with grain boundary sliding. Two cases of diffusion creep might thereby be differentiated, one in which diffusive mass transfer is causing a change in grain shape and grain boundary sliding is a local accommodating mechanism (Lifshitz sliding Langdon, 2006) and another in which grain boundary sliding is the dominate strain-accommodating mechanism with diffusive mass transfer ensuring strain compatibility at the grain scale (Rachinger sliding, Langdon, 2006). The relative importance of these processes has been discussed by Paterson (1990, 1995), and for the sake of simplicity, we implicitly include the operation of grain boundary sliding when we speak of diffusion creep. Apart from being rate and temperature sensitive, the rheology of viscously deforming rocks is also observed to be material dependent (for a comprehensive list of flow-law parameters for different rock types see, e.g., Kohlstedt et al., 1995, Shaocheng and Bin, 2002, Bürgmann and Dresen, 2008, Burov, 2011, and references therein). Flow laws for viscous creep exist for different types of rocks, with the majority of these flow laws being determined for monomineralic materials.

In monomineralic aggregates at mid-crustal to lower crustal conditions, grain growth in monomineralic aggregates is assumed to be extensive and the resulting large grain size is expected to render diffusion creep less effi- 
cient than dislocation creep (e.g., Brodie and Rutter, 1987; Paterson, 1990). Insights into deformation mechanisms, slip systems, and flow-law parameters have been obtained from experimental studies, e.g., for plagioclase: Tullis and Yund (1985), Shaocheng and Mainprice (1987), Tullis and Yund (1991), Dimanov et al. (1999), Rybacki and Dresen (2000), Stünitz and Tullis (2001), Stünitz et al. (2003), Ji et al. (2004), and Barreiro et al. (2007); for pyroxene: Lallemant (1978), Kolle and Blacic (1982), Raterron and Jaoul (1991), Mauler et al. (2000), Bystricky and Mackwell (2001), HierMajumder et al. (2005), Chen et al. (2006), and Zhang et al. (2006).

For polyphase mixtures of gabbroic composition, data from high-temperature deformation experiments are published by Dimanov et al. $(2003,2007)$ and Dimanov and Dresen (2005). Depending on the grain size, the differential stress, and the volume fraction of pyroxene (as the stronger phase in their pyroxene-plagioclase mixtures), the dominant deformation mechanism identified by these authors is either diffusion creep or dislocation creep. The strain rate of the two-phase aggregates is thereby suggested to be a combination of the strain rates of the individual phases; e.g., Dimanov et al. (2003). No mineral reactions were observed in these experiments. In somewhat lower-temperature experiments and mostly under hydrous conditions, Rutter et al. (1985), Getsinger and Hirth (2014), and Stünitz and Tullis (2001) performed deformation experiments with syn-kinematic hydration reactions. Phase mixing was found to be (partly) due to the nucleation of new phases. The authors suggest that the dominant deformation mechanism is grain-size-sensitive creep by a mix of diffusion creep and grain boundary sliding. Rutter et al. (1985) state explicitly that they interpret diffusion creep in the sense of dissolution-precipitation creep.

In polymineralic mixtures, several processes are known to influence the deformability and the dominating deformation mechanism of the bulk aggregate. The occurrence of mineral reactions and nucleation causes grain size reduction (e.g., Brodie and Rutter, 1987; Fitz Gerald and Stünitz, 1993; Newman et al., 1999; Handy and Stünitz, 2002; de Ronde et al., 2005) and can lead to (further) phase mixing, whereas grain pinning due to secondary phases is likely to impede grain growth (e.g., Olgaard and Evans, 1986; Berger and Herwegh, 2004; Linckens et al., 2011). Furthermore it has been suggested that under certain conditions during diffusion creep, the convergence and divergence rate between two different mineral phases can be faster than between grains of the same mineral phase (e.g., Hickman and Evans, 1991; Wheeler, 1992; Sundberg and Cooper, 2008). The result is more efficient strain accumulation in polymineralic areas compared to monomineralic ones. All these factors enhance diffusion creep rates and may thus lead to a switch of the dominant deformation mechanism from dislocation creep in monomineralic layers to diffusion creep in polymineralic ones (Etheridge and Wilkie, 1979; Mehl and Hirth, 2008; Linckens et al., 2011; Kilian et al., 2011).
In the absence of fluids, metastable mineral assemblages can be preserved over long time periods (e.g., Jamtveit et al., 2016). When fluids infiltrate, mineral reactions take place. Under deviatoric stress conditions, deformation is frequently localized along these zones of fluid infiltration and metamorphic reactions (e.g., Austrheim, 1987). A positive feedback between deformation and metamorphic reactions has been recognized for some time but the exact mechanisms of the interaction are still not sufficiently understood. The positive feedback with metamorphic reactions may not be the same for all deformation mechanisms and thus the syn-kinematic occurrence of mineral reactions is a factor that can influence the dominance of a certain deformation mechanism. It has been shown by the experiments of, e.g., Linckens et al. (2014) and Cross and Skemer (2017) that in the absence of fluids and mineral reactions, phase mixing is seen to be inefficient and necessitates shear strains of $>17$ in the case of Cross and Skemer (2017). This is in contrast to fluid-assisted deformation in polymineralic rocks, which are described to have a strong tendency for phase mixing (Kruse and Stünitz, 1999; Kilian et al., 2011; Precigout and Stünitz, 2016). Thus, strain may preferentially localize into wet and/or reactive regions of the lithosphere, promoted by (as mentioned previously) phase mixing and grain size reduction.

In the presence of fluids, mafic rocks are particularly susceptible to reactions during changing temperatures and pressures, representing a suitable material to study the interplay between reaction and deformation. That high strain zones such as ultramylonites usually consist of a phase mixture indicates their ability to deform at higher strain rates (or lower stresses) than monomineralic aggregates and emphasizes their importance for localizing deformation. In this study, we present results from deformation experiments on water-added plagioclase-pyroxene mixtures. At the imposed pressure-temperature conditions of $\sim 1.0-1.5 \mathrm{GPa}$ and $800^{\circ} \mathrm{C}$, deformation takes place within the lower temperature range of the viscous regime. The metastability of the starting material in the $\mathrm{H}_{2} \mathrm{O}$-present system causes synkinematic mineral reactions, thus facilitating the interplay between reaction and deformation in the experiments.

\section{Materials and methods}

\subsection{Experiments}

\subsubsection{Starting materials}

Experiments are performed on five different starting materials (the composition of starting material and chemical composition of minerals are given in Table 1; mineral abbreviations after Whitney and Evans, 2010).

i. MD: crushed Maryland diabase (Kronenberg and Shelton, 1980; Marti et al., 2017) using a grain size fraction $\leq 125 \mu \mathrm{m}$. The Maryland diabase starting material has a 
Table 1. Mineral composition. Representative mineral measurements as normalized oxide wt $\%$ and as calculated stoichiometric mineral composition for the different starting materials. All $\mathrm{Fe}$ is taken as $\mathrm{Fe}^{2+}$ due to the reducing environment in the sample assembly.

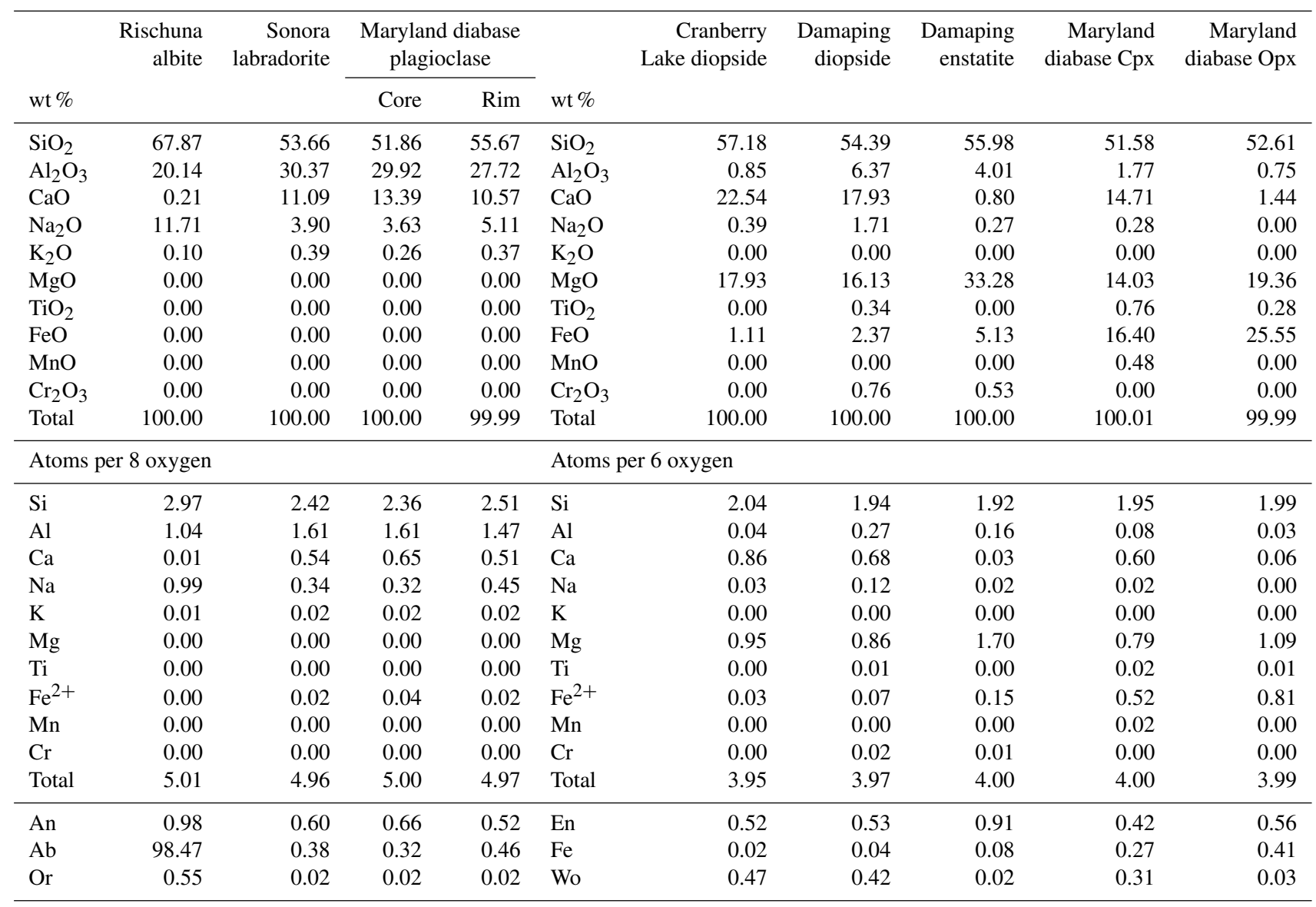

modal composition of plagioclase $\sim 57 \%$ vol, clinopyroxene $\sim 32 \%$ vol, orthopyroxene $\sim 8 \%$ vol, and accessories $\sim 3 \%$ vol (Qz, Kfs, Ilm, Mag, Bt, Ap).

ii. An60+En: synthetic mixture of Sonora labradorite $(\sim$ An60) and Damaping enstatite powder; grain size fraction of $\sim 2-125$ and $40-180 \mu \mathrm{m}$.

iii. An60+Di: synthetic mixture of Sonora labradorite and Damaping diopside powder; grain size fraction of $\sim 2-$ $125 \mu \mathrm{m}$.

iv. An60+Di: synthetic mixture of Sonora labradorite and Cranberry Lake diopside powder; grain size fraction of $\sim 2-125$ and $40-125 \mu \mathrm{m}$.

v. Ab+En: synthetic mixture of Alpe Rischuna albite $(\sim$ Ab98) and Damaping enstatite powder; grain size fraction of $\leq 125$ and $40-180 \mu \mathrm{m}$.

A detailed description of the sample preparation can be found in the Appendix. Synthetic plagioclase-pyroxene powders are mixed with phase proportions of $\sim 57 \%$ vol plagioclase to $43 \%$ vol pyroxene. Either $0.2 \mu \mathrm{L}(0.18 \mathrm{wt} \%)$ or $0.12 \mu \mathrm{L}(0.11 \mathrm{wt} \%) \mathrm{H}_{2} \mathrm{O}$ is added to the sample.

\subsubsection{Experimental conditions and sample assembly}

Experiments are performed using the Griggs-type deformation apparatus at the University of Troms $\varnothing$, Norway. Experiments are run at confining pressures $(\mathrm{Pc})$ of $\sim 1.0$ and $1.5 \mathrm{GPa}$, temperatures $(T)$ of $800^{\circ} \mathrm{C}$, and (axial) displacement rates of $\sim 2 \times 10^{-8}$ to $2 \times 10^{-9} \mathrm{~ms}^{-1}$, resulting in bulk strain rates of $\sim 3 \times 10^{-5}$ to $3 \times 10^{-6} \mathrm{~s}^{-1}$. General shear type of flow is achieved by placing the rock powder $(0.11 \mathrm{~g})$ between cylindrical alumina forcing blocks (diameter of $6.33 \mathrm{~mm}$ ) precut at $45^{\circ}$ with respect to the load axis (Appendix Fig. A1). Descriptions of the experimental setup, data recording, and data treatment can be found in the Appendix Sect. A1-A3, and experimental conditions are listed in Table 2.

\subsection{Strain determination}

The thickness of the shear zone (measured normal to the shear plane) at the hit point is th $=0.75 \pm 0.03 \mathrm{~mm}$. During the experiment, $\sim 86 \pm 3 \%$ of the axial displacement is accommodated as shear displacement within the shear zone, and $\sim 14 \pm 3 \%$ is accommodated as plane strain thinning of 
Table 2. List of experiments.

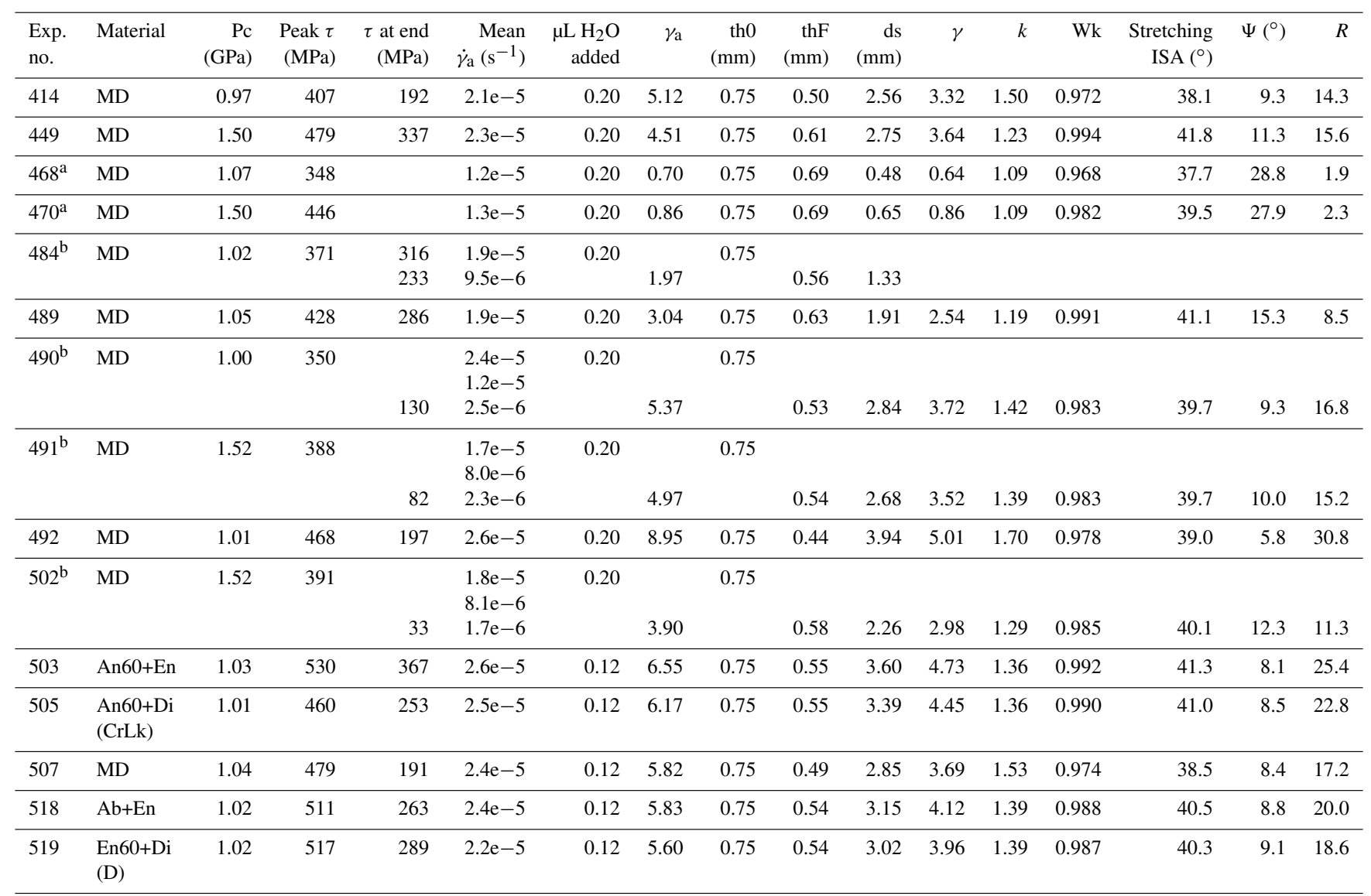

Pc: confining pressure, $\tau$ : shear stress, $\dot{\gamma}_{\mathrm{a}}$ : apparent shear strain rate, th0: shear zone thickness at experiment start, thF: shear zone thickness at experiment end, ds: shear displacement, $\gamma$ : simple shear component of total strain, $k$ : pure shear component of total strain, Wk: vorticity number, $\Psi$ : finite stretching direction, $R$ : ratio strain ellipse major vs. minor axis. Angles for stretching ISA and $\Psi$ are given with from east $\left(0^{\circ}\right)$ increasing counterclockwise. MD: Maryland diabase, slab: Sonora labradorite,

En: Damaping enstatite, Di(CrLk): Cranberry Lake diopside, Di(D): Damaping diopside, Ab: Alpe Rischuna albite. ${ }^{\text {a }}$ Experiment terminated at peak stress.

${ }^{\mathrm{b}}$ Displacement rate stepping test.

the shear zone. As in previous experiments, the shear zone thickness decreases linearly with the applied axial displacement (see Marti et al., 2017).

The shear strain is presented as apparent shear strain, $\gamma_{\mathrm{a}}$, and calculated as the sum of the incremental shear displacements divided by the instantaneous shear zone thickness; strain rates are given as apparent shear strain rates, $\dot{\gamma}_{\mathrm{a}}$ (see Marti et al., 2017). $\gamma_{a}$ is not a direct measure of the simple shear component in the general shear progressive deformation and should not be used to derive the strain ellipsoid or other strain-related parameters. Instead, the procedure described by Fossen and Tikoff (1993) and Tikoff (1995) is adopted to calculate the true simple shear component $(\gamma)$ from the general shear deformation and used to calculate parameters such as the instantaneous stretching axes (ISAs), the orientation of the finite stretching direction, the kinematic vorticity number, and the strain ratio given by the ratio of the long to short axis of the strain ellipsoid (Table 2). All strains and strain-related parameters are calculated for bulk homo- geneous sample deformation and do not take into account strain localization.

\subsection{Image analysis}

After the experiments, samples are immersed in epoxy, cut parallel (in some cases also normal to the shear direction), and prepared to polished thin sections. A polarized light microscope, scanning electron microscope (SEM), and transmission electron microscope (TEM) are used for sample analysis. Grain size and surface fabric are determined as described in Appendix Sect. A5.

A special method is developed to study the amphibole coronas that grow on pyroxene porpyhroclasts. Corona thickness is measured as a function of orientation around the clasts (Fig. 1). To this end, phase maps of pyroxene and amphibole are created (as described in Appendix Sect. A5). Where amphibole coronas of neighboring pyroxene clasts are in contact, individual pyroxene-amphibole pairs have to be separated manually. Manual separation and cleaning was per- 


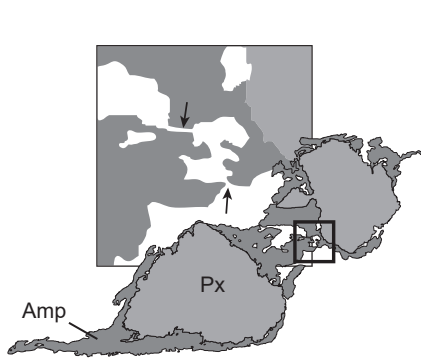

(a)

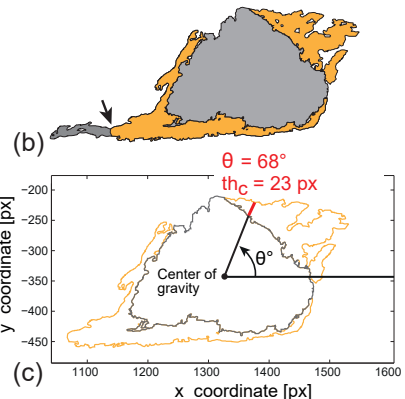

Figure 1. Analysis of amphibole corona thickness. (a) Digital phase map of segmented pyroxene (Px) clasts and associated amphibole (Amp) coronas. Where adjacent coronas are in contact, they are separated manually (close-up, black arrows). (b) Long "tails" of Amp growing in low stress sites around clasts are eventually "cut" (black arrow) if they extend too far away from the clast. (c) Corona thickness, thc $(\theta)$, is determined from the polar coordinates of the aggregate and clast outline as a function of the angle $\theta\left(0^{\circ}<\theta<360^{\circ}\right)$, with $\theta$ running counterclockwise from the horizontal.

formed by visual inspection and correlation of the original BSE image with the corresponding segmentation. Where necessary, the segmentation was corrected and cleaned with the pencil tool in Photoshop ${ }^{\circledR}$. Clean phase maps contain segmented pyroxene and amphibole phases, and each pyroxene grain is in contact only with its own amphibole corona. The $x-y$ coordinates of the clast (pyroxene) and the aggregate (pyroxene + corona) outlines are measured and exported using Fiji and a modified version of the Jazy XY export macro (by Rüdiger Kilian, available at https://github. com/kilir/Jazy_macros; last access: September 2016). Using a MATLAB script (available from the author upon request), the $x-y$ coordinates of clast and aggregate outlines are converted to polar coordinates $(r-\theta)$, and the corona thickness, $\operatorname{thc}(\theta)$, is determined at each point along the pyroxene clast as the shortest distance between the clast to the aggregate outline (Fig. 1c) as a function of $\theta$. The angle runs counterclockwise from the horizontal. This approach yields good results in which coronas follow the clast shape, but tends to underestimate corona thickness at which the corona becomes very elongated as, e.g., in "tails" around the clasts. Note that where tails grew extensively long, they were eventually cut so that the analysis does not include the whole tail length (Fig. 1b).

For the interpretation of the amphibole corona evolution it is important to have knowledge of the course and the different stages of an experiment (the details of which are listed in the Appendix). Due to the experimental procedure, the deformation stage is always preceded by an initial hydrostatic part ("lead run-in"; Appendix Fig. A1c) in which the sample is held at approximately hydrostatic conditions for $24-30 \mathrm{~h}$. During the initial lead run-in mineral reactions commence prior to sample deformation.

\section{Results}

\subsection{Mechanical data}

For all experiments, the mechanical data plotted as shear stress, $\tau$, vs. apparent shear strain, $\gamma_{\mathrm{a}}$, show a curve with an initial steep increase in shear stress, reaching a peak value usually after $\sim \gamma_{\mathrm{a}}$ of $0.8-1.0$ (Fig. 2). Peak stress is followed by a slow decrease, often approaching a quasi-steadystate shear stress value from $\gamma_{\mathrm{a}} \approx 4$ onwards. The samples with $0.12 \mu \mathrm{L} \mathrm{H}_{2} \mathrm{O}$ added show higher peak stresses and a more rapid shear stress decrease thereafter compared to samples with $0.2 \mu \mathrm{L} \mathrm{H}_{2} \mathrm{O}$ added. For the Maryland diabase samples (Fig. 2a) at $\mathrm{Pc} \approx 1.0 \mathrm{GPa}$, the sample with $0.12 \mu \mathrm{L} \mathrm{\textrm {H } _ { 2 } \mathrm { O }}$ reaches a higher peak stress, but after an additional $\sim 0.5 \gamma_{\mathrm{a}}$, it drops to a value similar to the samples with $0.2 \mu \mathrm{L} \mathrm{H}_{2} \mathrm{O}$. Sample strengths of Maryland diabase at 1.0 and $1.5 \mathrm{GPa}$ reach the same peak stress, but the $1.0 \mathrm{GPa}$ experiments weaken more rapidly within the attained strain range.

The synthetic plagioclase-pyroxene mixtures (Fig. 2b) show similar peak stress values (460-530 MPa) and all but the An60+En mixture attain similar flow stresses. The synthetic mixtures generally support $\sim 60-110 \mathrm{MPa}$ higher shear stresses than the Maryland diabase samples (compare Fig. 2a and b). At peak stress, the synthetic mixtures (samples 503, 518, and 519) reach differential stress values near the Goetze criterion. According to Kohlstedt et al. (1995), the Goetze criterion, $\Delta \sigma \leq \mathrm{Pc}$, is an empirically defined stress range at which rocks are expected to deform plastically. However, due to the significant weakening subsequent to peak stress, many samples that start above the Goetze criterion then fall substantially below it. The Maryland diabase samples all stay below the Goetze criterion for all stages of deformation.

Strain rate stepping tests on Maryland diabase sample material at $\mathrm{Pc} \approx 1.0$ and $1.5 \mathrm{GPa}$ have been performed (Fig. $2 \mathrm{c}$ ) to test the sensitivity of shear stress on strain rate. Stress exponents, $n$, of $n=1.9$ and $n=1.4$ are obtained for experiments at $\mathrm{Pc} \approx 1.0$ and $1.5 \mathrm{GPa}$, respectively (Fig. 3 ).

\subsection{Microstructures}

In all experiments strain is partitioned into a network of shear bands (Figs. 4, 5). Their thickness is variable but the main shear band strands usually have a thickness of the order of 40-150 $\mu \mathrm{m}$ (e.g., Fig. 5d, j) and are characterized by strong grain size reduction (Fig. 5b, e, k). The following hydration reactions are observed within shear bands and in low strain lenses:

$$
\begin{aligned}
& \mathrm{Px}+\mathrm{Pl}+\mathrm{H}_{2} \mathrm{O} \longrightarrow \mathrm{Amp}+\mathrm{Qz}, \\
& \mathrm{Pl}_{1}+\mathrm{H}_{2} \mathrm{O} \longrightarrow \mathrm{Pl}_{2}+\mathrm{Zo}+\mathrm{Qz}+\mathrm{Ky},
\end{aligned}
$$

where $\mathrm{Pl}_{2}$ has a lower anorthite component than $\mathrm{Pl}_{1}$.

In Maryland diabase samples, both Reactions (R1) and (R2) occur pervasively, with Reaction (R1) being the more 

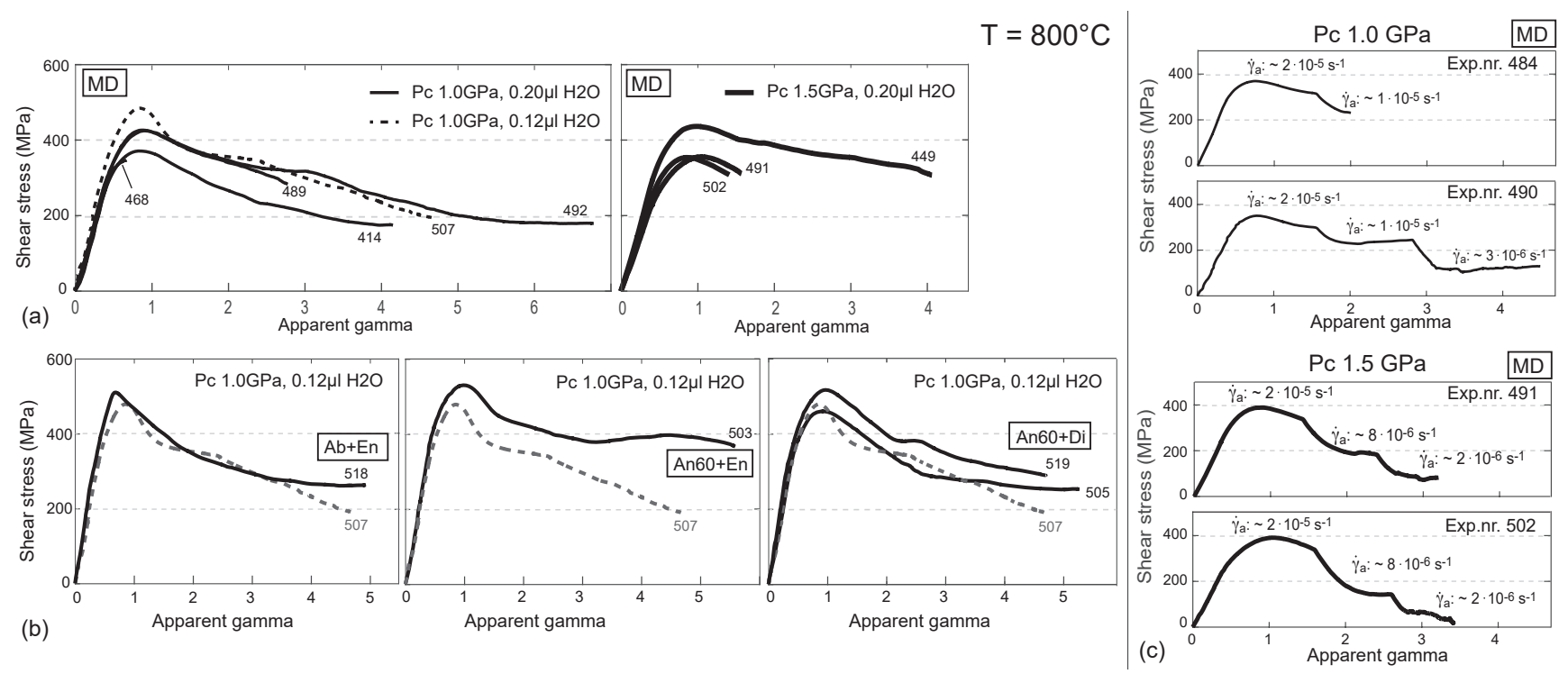

Figure 2. Mechanical data. Shear stress, $\tau(\mathrm{MPa})$, versus apparent shear strain, $\gamma_{\mathrm{a}}$. Stippled line: experiment 507 (MD) for reference. (a) Maryland diabase (MD) experiments for different confining pressures, Pc (GPa), and water contents. (b) Experiments using different Pl-Px mixtures and constant Pc and water content. (c) Displacement rate stepping tests on MD sample material for experiments performed at different confining pressures.

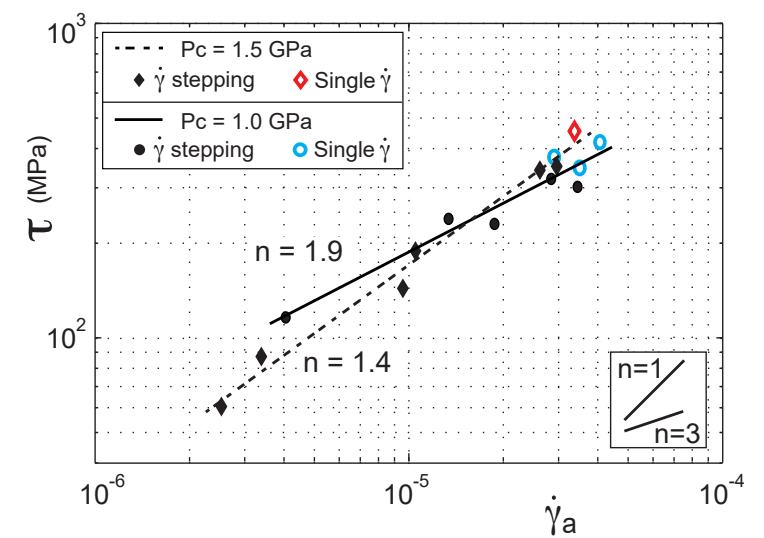

Figure 3. Determination of stress exponents. Shear stress, $\tau$ (MPa), versus apparent shear strain rate, $\dot{\gamma}_{\mathrm{a}}$. Two stress exponents, $n$, are obtained using constant strain rate data and strain rate stepping experiments. For experiments at confining pressures, $\mathrm{Pc}=1.0 \mathrm{GPa}$, $n=1.9$; for $\mathrm{Pc}=1.5 \mathrm{GPa}, n=1.4$. Data for $\mathrm{Pc}=1.0 \mathrm{GPa}$ from Marti et al. (2017).

prominent one. Amphibole grows as reaction coronas on pyroxene clasts and as aggregates, often mixed with quartz, inside shear bands (Figs. 5b, 6a, c). Both Reactions (R1) and (R2) initiated during the hydrostatic "lead run-in" (Appendix Fig. A1c). At the hit point, samples are fully compacted with only a few submicron-sized pores remaining. At peak stress, the volume percentage of hydrous reaction products for experiments at $1.0 \mathrm{GPa} \mathrm{Pc}$ is $\sim 7 \%$ (sample 468, duration $38 \mathrm{~h}$ : lead run-in and subsequent deformation to peak stress)

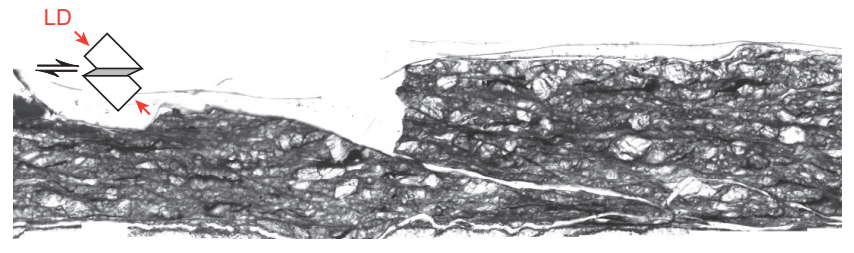

Figure 4. Shear zone overview. Micrograph of sample 492, plane polarized light. Strain localizes into a network of shear bands, anastomosing around low strain lenses identifiable by the large porphyroclasts. Sketch in the upper left shows the orientation of the micrograph with respect to the loading direction (LD) of the sample setup (Appendix Fig. A1).

and $\sim 19 \%$ for $1.5 \mathrm{GPa}$ Pc experiments (sample 470, duration $46.5 \mathrm{~h}$ : lead run-in and subsequent deformation to peak stress). In 1.0 GPa Pc experiments, the volume of hydrous reaction products reaches about 15-25\% for experiments with durations of $\sim 60-70 \mathrm{~h}$ (lead run-in and subsequent deformation to $\gamma_{\mathrm{a}} \approx 4$ to 6 ). In $1.5 \mathrm{GPa}$ Pc experiments, the volume of hydrous reaction products reaches up to $31 \%$.

Shear bands in Maryland diabase experiments are broad and subparallel to the shear zone boundaries (Fig. 5c), with an angle $\phi=3^{\circ}$ between the preferred orientation of shear bands and shear zone boundaries (see Fig. 5 for reference frame). Shear bands are mainly formed by grains with < $1 \mu \mathrm{m}$ diameter and frequently show a compositional layering between plagioclase-dominated and amphibole-dominated layers (Figs. 5b, 6a, b). Plagioclase layers are either monomineralic or show mixing with zoisite. In amphibole- 
Overview
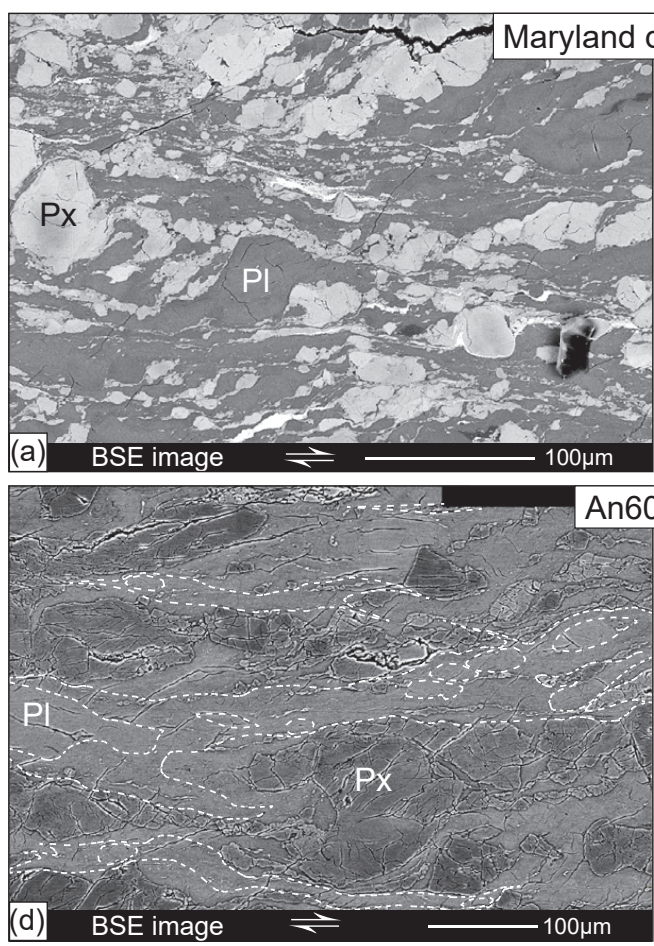

(b)

Shear band close-up
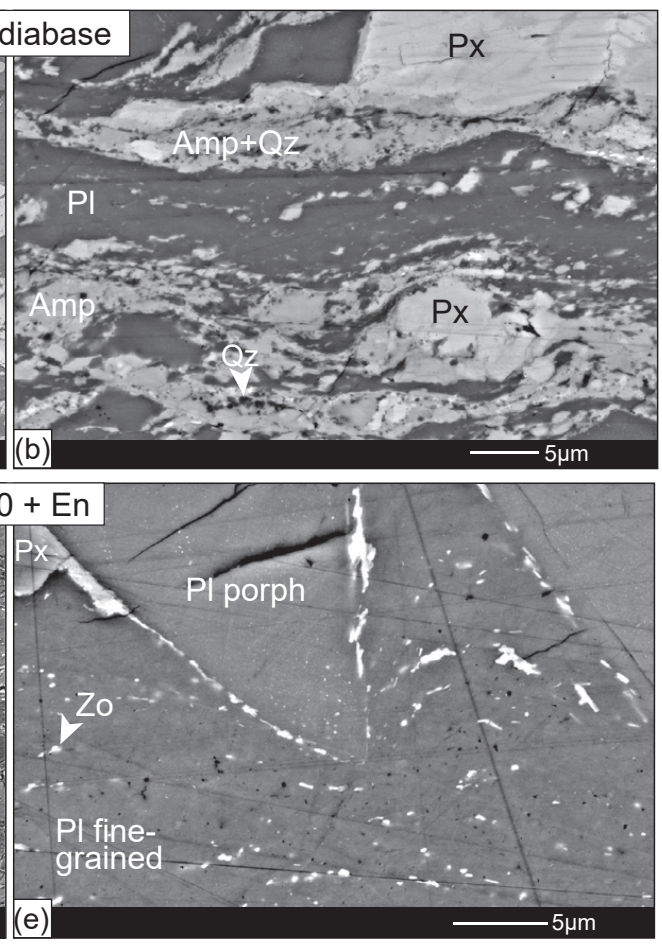

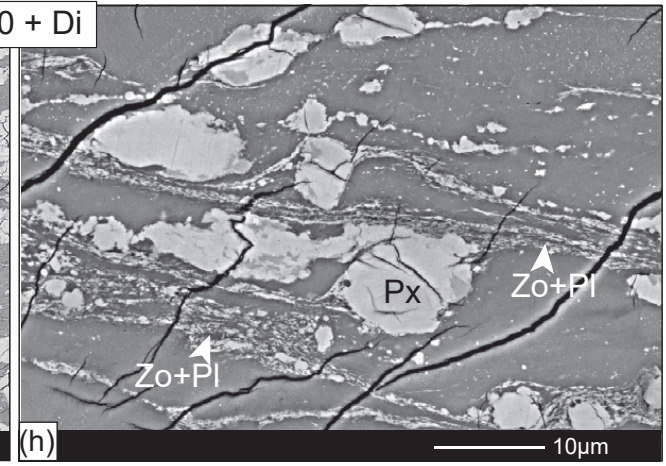

(f)
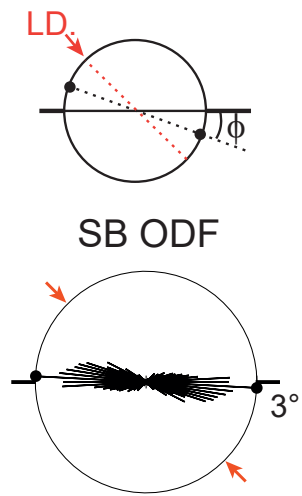

(c)
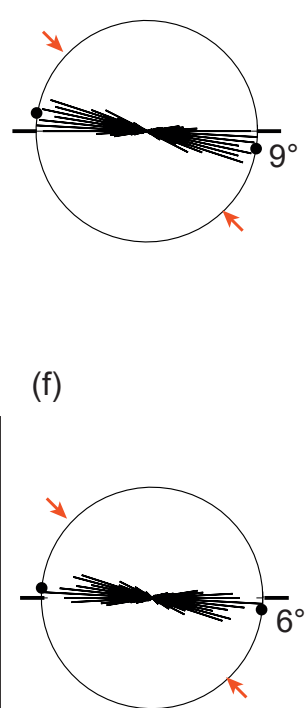

(i)

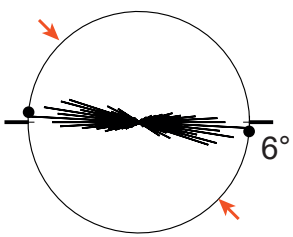

(I)

Figure 5. Microstructures of experiments at $\mathrm{Pc} \approx 1.0 \mathrm{GPa}$. (a-c) Maryland diabase sample material. (b) Shear bands are fine-grained and often polymineralic, with the main constituents Pl, Amp, and Qz. (d-f) An60+En sample material. Due to the low iron content, pyroxene appears darker than the plagioclase in BSE-SEM images. In panels (d) and (j), shear bands are traced with white dotted lines. (e) Finegrained $\mathrm{Pl}+$ Zo in a shear band next to a Pl porphyroclast. (g-i) An60+Di sample material. (j-l) Ab+En sample material. (h) EBSD band contrast image with transparent phase map overlay. Plagioclase appears blueish, pyroxene yellowish. Rose diagrams represent the orientation of the shear bands, and black dots indicate the preferred trend of shear band segments. Red arrows indicate the direction of loading. The angle, $\phi$, between the shear zone boundary (or forcing block) and the preferred shear band trend is indicated. 

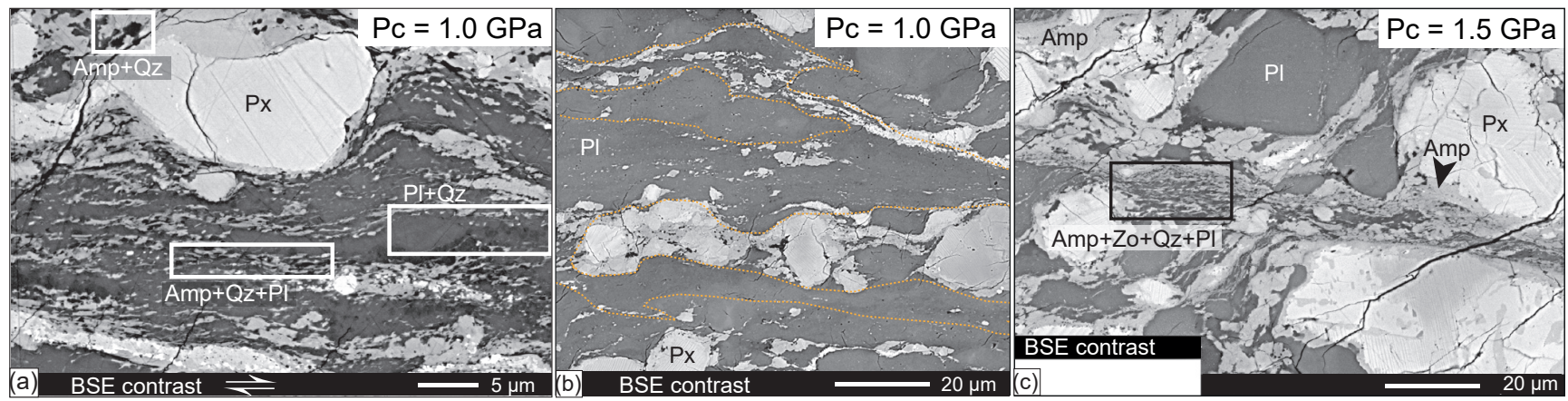

Figure 6. Distribution of phases in Maryland diabase. (a) Area of extensive phase mixing in a shear band: mixing of $\mathrm{Pl}+\mathrm{Qz}, \mathrm{Pl}+\mathrm{Zo}$, and Amp + Qz. Mixing between Amp and Pl is less frequent. Px clasts show Amp coronas and asymmetric Amp tails. (b) Area where shear bands (outlined with dashed orange lines) are predominantly composed of polycrystalline Pl. (c) Extensive phase mixing between $\mathrm{Amp}+\mathrm{Zo}+\mathrm{Qz}(+\mathrm{Pl})$ within shear bands. Px clasts show Amp coronas and asymmetric Amp tails.

dominated layers, amphibole frequently occurs together with quartz. Mixing between amphibole and plagioclase is subordinate.

In synthetic mixtures of An60+En and An60+Di (Fig. 5di), Reaction (R2) is the dominant hydration reaction. The volume of hydrous reaction products reaches $1-9 \%$ for experiments with durations of $\sim 66-69 \mathrm{~h}$ (lead run-in and subsequent deformation). In the An60+En mixture, shear bands are somewhat narrower and more anastomosing. At an angle of $\phi=9^{\circ}$, they are also more inclined to the shear zone boundaries compared to the other samples (Fig. 5f). Shear bands in both An60+En and An60+Di mixtures are mainly formed by fine-grained $(<1 \mu \mathrm{m})$ plagioclase and zoisite.

The zoisite reaction predicts the formation of a new plagioclase with a lower anorthite component. The fine grain size within shear bands does not allow for quantitative EDS measurements, but backscattered electron (BSE) images reveal lower $\mathrm{Z}$ contrast (lower anorthite contents) for plagioclase within shear bands compared to plagioclase porphyroclasts (Fig. 5e). Semiquantitative EDS measurements yield a decrease in anorthite component from $\sim \operatorname{An}(60)$ (starting composition) to $\sim \operatorname{An}(52-55)$ for grains within shear bands (Fig. 7).

In the Ab+En sample, shear bands are broad and subparallel to the shear zone boundaries, with $\phi=6^{\circ}$ (Fig. 5l). Shear bands are predominantly composed of fine-grained plagioclase (Fig. 5k) with sizes $<2 \mu \mathrm{m}$. No difference in composition between plagioclase porphyroclasts and finegrained plagioclase within shear bands was detected. In highresolution BSE images, a fine-grained phase with a $\mathrm{Z}$ contrast similar to enstatite is observed. Due to the small grain size EDS measurements are extremely challenging but point to a new type of pyroxene with a somewhat higher $\mathrm{Si}$ and $\mathrm{Na}$ component.

In all experiments (Maryland diabase and synthetic mixtures), plagioclase shows extensive grain size refinement. Porphyroclasts are replaced by fine-grained plagioclase, nu- cleating mainly along porphyroclast rims and along straight internal trails, which are thought to represent former fractures (Fig. 5k). The newly nucleated grains generally show a lower anorthite component than the plagioclase in the starting material (Fig. 7). In experiments on Maryland diabase, pyroxene grain size reduction is largely caused by the pyroxene-consuming reaction to Amp (Reaction R1, Figs. 5b, 6). In the synthetic mixtures, however, much of the grain size reduction of pyroxene is caused by fracturing.

The main difference between the microstructures developed at 1.0 and 1.5 GPa Pc (Maryland diabase experiments) is the increased amount of reaction products at higher Pc (Fig. 6). Zoisite and amphibole form more abundantly at $1.5 \mathrm{GPa}$ and amphibole corona surround pyroxene porphyroclasts in early stages of the experiments. Shear bands at $\mathrm{Pc} \approx 1.0 \mathrm{GPa}$ are mainly composed of a fine-grained mixture of $\mathrm{Pl}+\mathrm{Amp}+\mathrm{Qz}+\mathrm{Zo}$ (in order of abundance) compared to $\mathrm{Amp}+\mathrm{Pl}+\mathrm{Zo}+\mathrm{Qz}$ (again in order of abundance) at $1.5 \mathrm{GPa}$. Additionally, shear bands are somewhat narrower and more inclined to the shear zone boundaries at higher Pc (compare Marti et al., 2017).

\subsection{Amphibole chemistry}

For Maryland diabase experiments at $1.0 \mathrm{GPa}$, two groups of amphibole are recognized, differing in their $\mathrm{Al}$ and $\mathrm{Mg}$ per formula unit (pfu), and in their $\mathrm{Na}$ to $\mathrm{Al}$ ratio (Fig. 8, Tables 3 and S1 in the Supplement). The amphiboles are classified as ranging between tschermakite and Mg hornblende. When labeling the amphibole measurements according to their 2-D neighborhood as observed in the thin section, the $\mathrm{Al}$ and $\mathrm{Mg}$ contents shows a consistent pattern in which high Al-low $\mathrm{Mg}$ amphiboles grow in plagioclase-dominated areas (Fig. 8bd). The $\mathrm{Si}$ and $\mathrm{Ca}$ contents thereby show no systematic difference between the different grain neighborhoods. Table S1 lists amphibole and plagioclase (starting material and newly nucleated) compositions. 

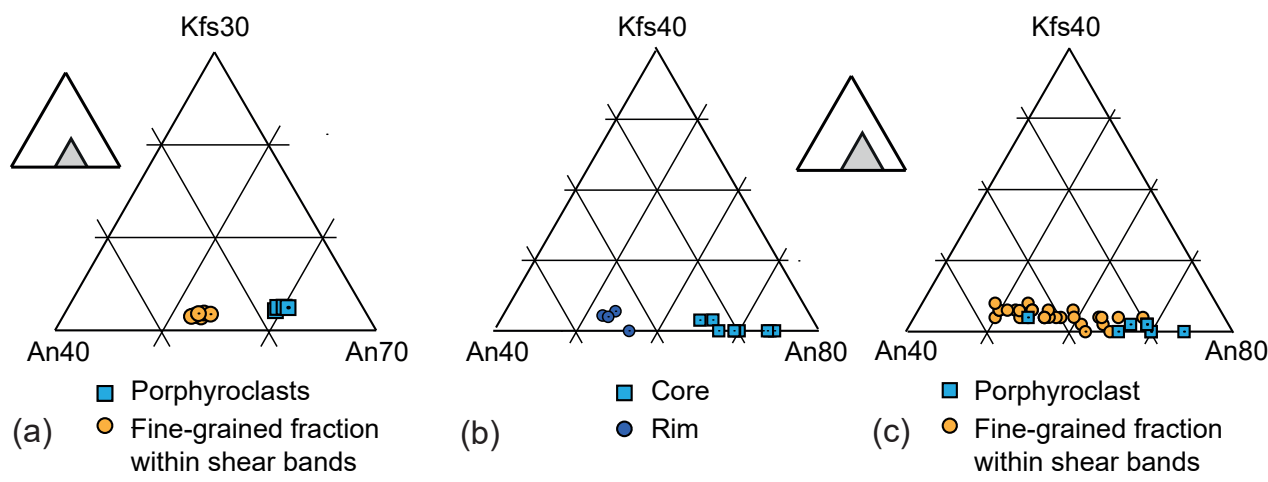

Figure 7. Plagioclase chemical compositions. (a) Sonora labradorite in An60+Di experiment runs. (b) Maryland diabase starting material. (c) Maryland diabase after the experiment. Porphyroclasts vs. small new grain fraction found in shear bands.
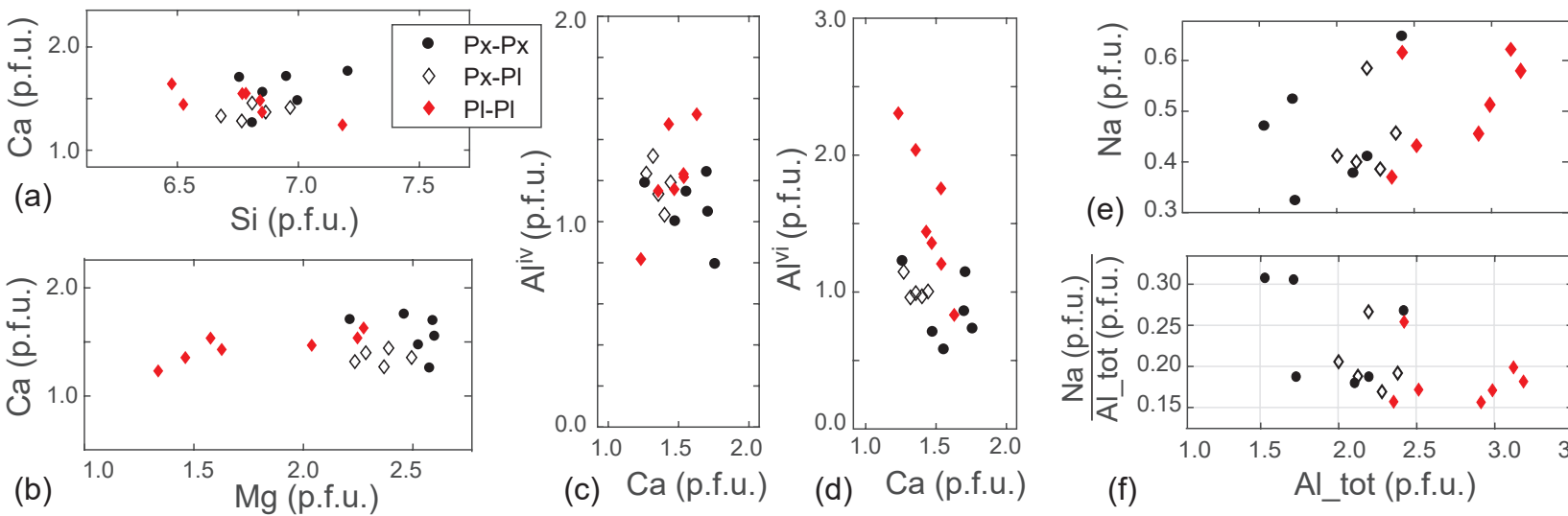

Figure 8. Amphibole chemistry. Amphibole grains of Maryland diabase experiments performed at $\mathrm{Pc} \approx 1.0 \mathrm{GPa}$. Measurements are grouped according to their neighborhood: Px-Px: pyroxene-dominated neighborhood. Px-Pl: amphibole grown between pyroxene and plagioclase grains; Pl-Pl: plagioclase-dominated neighborhood. (a) Ca vs. Si per formula unit (pfu). (b) Ca vs. Mg. (c) Estimated Al ${ }^{\text {iv }}$ vs. Ca. (d) Estimated $\mathrm{Al}^{\mathrm{vi}}$ vs. Ca. (e) $\mathrm{Na}$ vs. Al (total). (f) $\mathrm{Na}$ per $\mathrm{Al}$ (total) ratio vs. Al (total).

Two groups of amphibole compositions are present, which can be distinguished by their Na per $\mathrm{Al}$ content ratio (Fig. 8e, f). The plagioclase of the Maryland diabase starting material has an anorthite component of $\sim \mathrm{An}(65-70)$, with thin rims of $\sim \mathrm{An}(52-56)$ (Fig. 7). The core's $\mathrm{Na}$ to $\mathrm{Al}$ ratio is thus $\sim 0.18-0.21$. Plagioclase is the sole provider for $\mathrm{Na}$ and $\mathrm{Al}$ in amphibole as the pyroxene in the starting material shows only trace amounts of these elements. Most amphibole measurements show an $\mathrm{Na}$ : Al ratio of 0.16-0.21 (Fig. 8f), consistent with reaction (R1) and the consumption of a plagioclase with a composition of $\sim \operatorname{An}(65-70)$. The second type of amphibole, with $\mathrm{Na}: \mathrm{Al}$ ratios $>0.25$, is comparable to the $\mathrm{Na}: \mathrm{Al}$ ratio of the starting plagioclase rim composition of $\sim \mathrm{An}(52-56$ ) (resulting in $\mathrm{Na}: \mathrm{Al}$ ratios of $\sim 0.28-0.32$ ) and thus again would be compatible with the plagioclaseconsuming, amphibole-forming Reaction (R1).

\subsection{Shear bands}

\subsubsection{Nanostructure of plagioclase within shear bands}

TEM images are presented from shear bands formed within the Ab+En sample 518 (Fig. 9) and the Maryland diabase sample 414 (Fig. 10). For both samples, micrographs are obtained from foils cut normal to the shear zone boundaries and parallel to the shear direction. Figure 9a shows the interface between an albite porphyroclast and the fine-grained albite matrix of an adjacent shear band. The albite clast has a high defect density, whereby intragranular domains develop misorientations to each other, as seen in the bright-field image or from the rotation of diffraction spots (Fig. 9b). However, no recovery to form sub-grain walls is observed. Furthermore, the interface between the clast and the shear band is sharp and no bulges are observed (Fig. 9a). Within the shear band, 
Table 3. EDS measurements of Amp chemical compositions from samples deformed at $\mathrm{Pc} \approx 1.0 \mathrm{GPa}$.

\begin{tabular}{|c|c|c|c|c|}
\hline \multirow[b]{2}{*}{$\begin{array}{l}\text { wt } \%, \text { norma- } \\
\text { lized to } 98 \%\end{array}$} & \multicolumn{4}{|c|}{ Amphibole } \\
\hline & $\begin{array}{c}414 \mathrm{sm} \\
\text { tschermak. }\end{array}$ & $\begin{array}{r}414 \mathrm{sm} \\
\mathrm{Mg} \text { hornbl. }\end{array}$ & $\begin{array}{r}490 \mathrm{sm} \\
\text { Mg hornbl. }\end{array}$ & $\begin{array}{r}490 \mathrm{sm} \\
\text { tschermak. }\end{array}$ \\
\hline $\mathrm{SiO}_{2}$ & 45.18 & 45.72 & 47.76 & 47.31 \\
\hline $\mathrm{Al}_{2} \mathrm{O}_{3}$ & 17.13 & 14.13 & 13.06 & 17.73 \\
\hline $\mathrm{CaO}$ & 9.24 & 8.92 & 9.45 & 10.02 \\
\hline $\mathrm{Na}_{2} \mathrm{O}$ & 1.63 & 1.74 & 2.12 & 1.84 \\
\hline $\mathrm{K}_{2} \mathrm{O}$ & 1.26 & 0.86 & 0.89 & 0.90 \\
\hline $\mathrm{MgO}$ & 7.56 & 9.95 & 11.24 & 7.39 \\
\hline $\mathrm{TiO}_{2}$ & 0.00 & 1.78 & 0.00 & 0.00 \\
\hline $\mathrm{FeO}$ & 15.99 & 14.90 & 13.48 & 12.81 \\
\hline $\mathrm{MnO}$ & 0.00 & 0.00 & 0.00 & 0.00 \\
\hline $\mathrm{Cr}_{2} \mathrm{O}_{3}$ & 0.00 & 0.00 & 0.00 & 0.00 \\
\hline Total: & 97.99 & 98.00 & 97.99 & 98.00 \\
\hline \multicolumn{5}{|c|}{ Formula per 23 oxygen } \\
\hline $\mathrm{Si}$ & 6.59 & 6.76 & 6.89 & 6.77 \\
\hline $\mathrm{Ti}$ & 0.00 & 0.00 & 0.00 & 0.00 \\
\hline $\mathrm{Al}$ & 2.95 & 2.46 & 2.22 & 2.99 \\
\hline $\mathrm{Fe}^{3+}$ & 0.00 & 0.00 & 0.00 & 0.00 \\
\hline $\mathrm{Cr}$ & 0.00 & 0.00 & 0.00 & 0.00 \\
\hline $\mathrm{Mg}$ & 1.65 & 2.19 & 2.42 & 1.58 \\
\hline $\mathrm{Ca}$ & 1.45 & 1.41 & 1.46 & 1.54 \\
\hline $\mathrm{Mn}$ & 0.00 & 0.00 & 0.00 & 0.00 \\
\hline $\mathrm{Fe}^{2+}$ & 1.95 & 1.84 & 1.63 & 1.53 \\
\hline $\mathrm{Na}$ & 0.46 & 0.50 & 0.59 & 0.51 \\
\hline $\mathrm{K}$ & 0.23 & 0.16 & 0.16 & 0.16 \\
\hline Total & 15.28 & 15.34 & 15.38 & 15.08 \\
\hline
\end{tabular}

Amphibole classification after Hawthorne et al. (2012). Tschermak.: tschermakite, $\mathrm{Mg}$ hornbl.: magnesium hornblende. All $\mathrm{Fe}$ is taken as $\mathrm{Fe}^{2+}$ due to the reducing conditions in the sample assembly.

small pores are seen as pore trails along grain boundaries (Fig. 9c, d) oriented at a small angle to the expected $\sigma_{1}$.

The shear band formed in the Maryland diabase sample shows the typical compositional layering between plagioclase-dominated layers and amphibole $(+\mathrm{Qz})$ aggregates (Fig. 10a). Bright-field TEM images reveal largely defect-free grains (Fig. 10b, d) and grain sizes are similar for amphibole and plagioclase. Grain and phase boundaries are tight and porosity is scarce (Fig. 10c, d). Plagioclase grains are weakly anisotropic in shape (not perfectly equant) with a shape preferred orientation subparallel to the shear zone boundaries (Fig. 10b, d; compare Marti et al., 2017).

\subsubsection{Plagioclase grain size distribution within shear bands}

2-D grain size distributions (GSDs) are determined for plagioclase inside shear bands of the $\mathrm{Ab}+\mathrm{En}$ experiment 518 and the MD experiment 414 (Fig. 11). The distributions in the two samples are similar with somewhat higher frequencies in bins $>1 \mu \mathrm{m}$ for albite compared to the labradorites of the Maryland diabase sample. Due to the small grain sizes and extremely narrow grain boundaries, grains are difficult to identify on SEM images and there is some uncertainty con- cerning the measured GSDs inherent from the grain segmentation. Nonetheless, grains segmented from TEM and SEM images correlate well for the highest frequency bins. Measured on TEM and SEM images, the GSDs for sample 518 have modes at 0.51 and $0.36 \mu \mathrm{m}$, respectively. In sample 414, the GSDs have modes at 0.23 and $0.30 \mu \mathrm{m}$ (Fig. 11).

\subsubsection{Albite crystallographic preferred orientation}

Three EBSD maps are collected along one shear band in the $\mathrm{Ab}+\mathrm{En}$ sample 518. Orientation data of plagioclase from three distinct sites (Fig. 12) are used to test for the presence of a crystallographic preferred orientation (CPO). Grains are calculated with a threshold angle of $10^{\circ}$ and merged across boundaries consistent with the albite twin law. Porphyroclasts and their adjacent fragments as well as grains with $<2 \mu \mathrm{m}$ equivalent diameter and $<3$ points are excluded (Fig. 12b).

The pole figures (Fig. 12c), which combine the data of all three sites, show a weak but distinct CPO for which especially [010] and (010) show systematic arrangements of a maximum $\sim 35^{\circ}$ off the periphery and with a high angle to the trace of the shear band. [100] axes and poles to (110) form local maxima along the trace of the shear band plane. Inverse pole figures (IPF) (Fig. 12d) are plotted for each site individually. Reference directions for the IPF are $0^{\circ}$ (parallel to the global shear direction) and $90^{\circ}$ (normal to the global shear plane). Choosing, e.g., the bulk finite stretching direction $\left(+10^{\circ}\right)$ or the shear band trace $\left(-10^{\circ}\right)$ and their normals did not result in significantly different results. Maxima of all distributions have moderate strengths and occupy nearly identical positions for all sites and at each reference direction (showing the close similarity of the CPO developed in all three individual sites). For all distributions, the positions of maxima do not coincide with any common poles to low index planes or directions. Distributions with respect to the shear plane normal are strongest with pole maxima at $(-121)$ $\left(90^{\circ}\right.$ reference frame).

\subsection{Amphibole coronas}

Amphibole grows abundantly in experiments on Maryland diabase, especially at the higher Pc (e.g., Fig. 6c) for which pyroxene clasts are already surrounded by amphibole coronas in early stages of the experiment. It has been noted that whereas coronas seem to grow symmetrically during the hydrostatic stage of an experiment, they evolve to become narrower in high stress sites around their host porphyroclast and grow larger in the clast strain shadow during sample deformation (Fig. 13a). To quantify this corona thickness evolution, pyroxene clast-amphibole rim pairs from experiments performed at $\mathrm{Pc} \approx 1.5 \mathrm{GPa}$ were analyzed, studying the average amphibole corona thickness as a function of orientation around pyroxene porphyroclasts (Fig. 13). Coronas are measured at three different stages: at hydrostatic condi- 

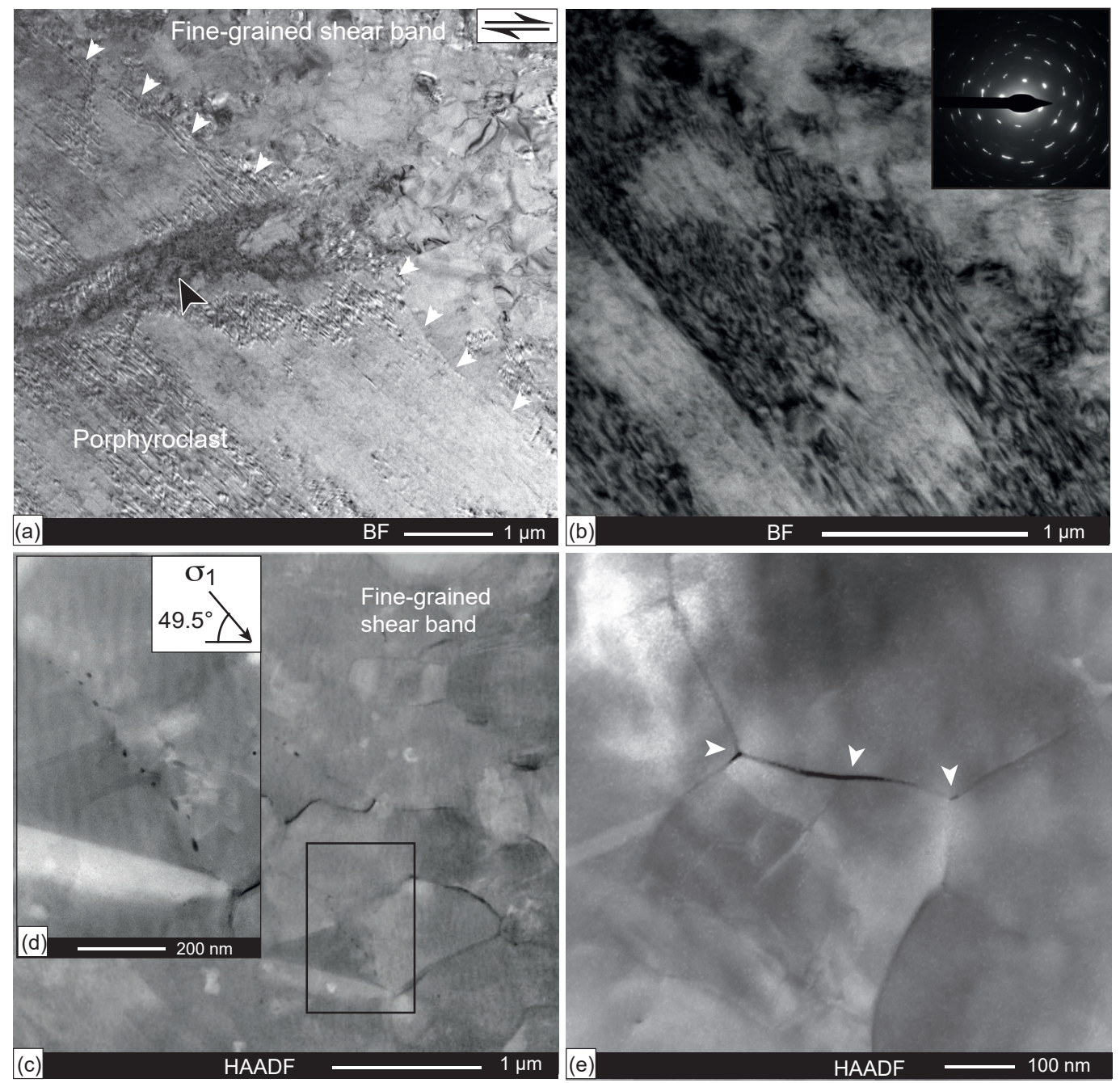

Figure 9. Nanostructures of shear bands in Ab+En sample. For sample 518, shear zone boundaries are horizontal and shear sense is dextral. (a) Bright-field (BF) image of a plagioclase porphyroclasts adjacent to a fine-grained shear band. White arrows mark the porphyroclastshear band interface. Black arrow points to a high defect density band within the clast. (b) BF image of the internal structure of porphyroclast showing high defect density. Twin lamellae run from the upper left to lower right. (c) HAADF image of a fine-grained plagioclase in a shear band. Black rectangle marks close-up view in panel (d). (d) HAADF image of a pore trail following several aligned grain boundaries. The local orientation of $\sigma_{1}$ is derived from the orientation of the ISA (Table 2). (e) HAADF image. White arrows point to porosity or opening sites developed along two triple junctions and a grain boundary.

tions $(\Delta \sigma \approx 0)$, at peak stress $\left(\Delta \sigma>0 ; \gamma_{\mathrm{a}} \approx 1\right)$, and after considerable deformation $\left(\Delta \sigma>0 ; \gamma_{\mathrm{a}} \approx 4\right)$ corresponding to three evolutionary stages of a typical high strain experiment (Appendix Fig. A1c). Accordingly, three cases are distinguished. The hydrostatic case represents the microstructural state at the hit point after the lead run-in. The peak stress case records the microstructural state at the time the sample has reached its maximum strength (including lead run-in and initial sample loading) and the deformed case represents the microstructure evolved after the sample underwent high shear strain (including lead run-in, sample yielding, and deformation; for an explanation on the nomenclature used see Appendix Fig. A1c).
At hydrostatic conditions (e.g., during the lead run-in), corona growth is symmetrical around the clasts, with an average thickness of 2.4 to $3.1 \mu \mathrm{m}$ (Fig. 13b). In the deformed case, the average corona thickness shows an overall monoclinic shape. Assuming that the microstructure after lead run-in (hydrostatic part) is approximately the same as that of the hydrostatic case sample, the corona thickness in the deformed sample is reduced by $\sim 0.5-2 \mu \mathrm{m}$ in directions close to the loading direction. Thickness is reduced in most directions except in the range of $346-53^{\circ}$ and $186-232^{\circ}$, where it is increased. On average, the corona thickness is reduced on clast surfaces facing the loading direction and increased at high angles to the loading direction. At peak stress the av- 

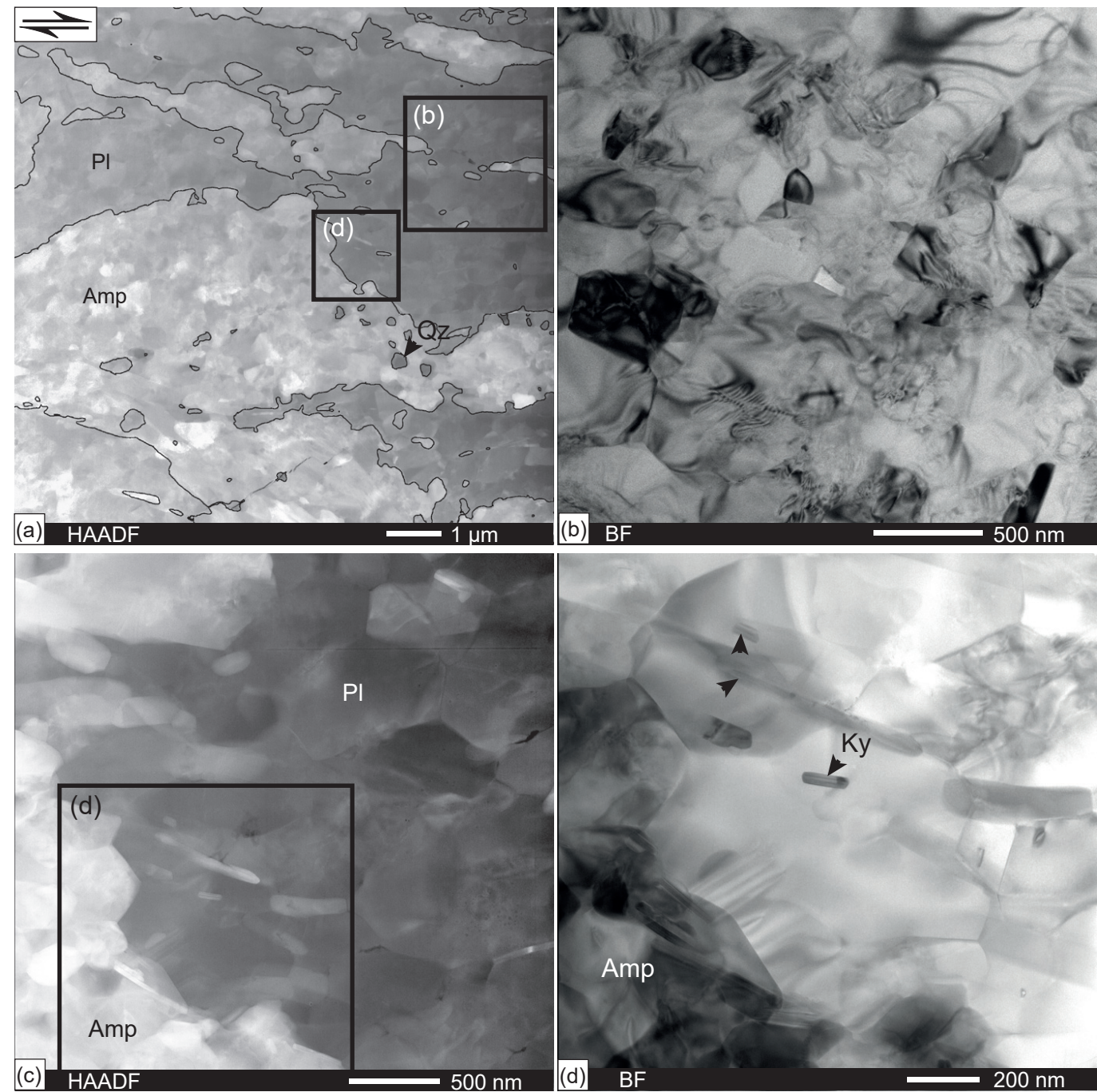

Figure 10. Nanostructure of shear bands in Maryland diabase sample. For sample 414, shear zone boundaries are horizontal and shear sense is dextral. (a) HAADF image, overview. Amp aggregates are traced with black lines for better visibility. Rectangles indicate areas shown in panels (b) and (d). (b) BF-TEM image of small (usually $\leq 600 \mathrm{~nm}$ ) plagioclase grains with low internal defect densities. Grain boundaries are tight and porosity is scarce. (c) HAADF image, overview. Black rectangle indicates area shown in panel (d). (d) BF-TEM image of a few Ky and Amp grains growing between Pl grains. The size of all phases is a few hundred nanometers, and grains have a low internal defect density.

erage corona thickness in the direction of loading is the same as in the hydrostatic case $(\sim 2.7 \mu \mathrm{m})$ but already increased in almost all other directions. Furthermore, despite the $23 \mathrm{~h}$ longer duration of the hydrostatic run compared to the peak stress run (Fig. 13d), coronas did not grow to larger thicknesses in the former.

Instantaneous stretching and shortening axes (ISAs), finite stretching directions, and vorticity numbers (Wk) are calculated for the peak stress and the deformed case (Fig. 13c). The orthorhombic shape of the peak stress corona curve is well described by the ISA, e.g., such that the long side is normal to the shortening ISA. After deformation, the long diameter of the monoclinic-shaped corona curve is oriented between the stretching ISA and the finite stretching direction. The short diameter corresponds to the shortening sector around the pyroxene clast. The direction of the maximum corona thickness is at a higher angle with respect to the shear plane than the finite stretching direction (Fig. 13b).

\section{Discussion}

\subsection{Physics and chemistry of grain size reduction}

There is a drastic grain size decrease (down to diameters $<2 \mu \mathrm{m}$ ) accompanied by the shear band formation (Figs. 5, 9-11). Fracturing as an important process of grain size re- 


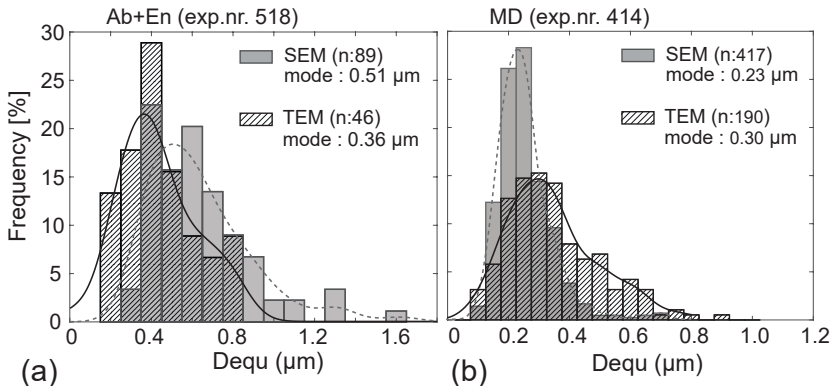

Figure 11. Grain size distributions of plagioclase in shear bands. (a) $\mathrm{Ab}+\mathrm{En}$ experiment 518 and (b) the Maryland diabase experiment 414. 2-D grain size distributions (GSDs) in both samples are determined on BSE-SEM images and TEM images separately. $n$ : number of grains; solid black (TEM) and dashed grey lines (SEM) are kernel density estimate fits to the GSDs and modes determined from the fit are given in the graph.

duction is only observed in the pyroxene grains of the synthetic mixtures (e.g., Fig. 12b). In these samples, pyroxene only participates in mineral reactions to a minor degree, and the plagioclase hydration Reaction (R2) is dominant (except for the $\mathrm{Ab}+\mathrm{En}$ sample). In contrast, pyroxene grains in experiments on Maryland diabase show grain size reduction by dissolution during the pyroxene-consuming Reaction (R1) to amphibole.

Fracturing only minorly contributes to the grain size reduction of plagioclase. Instead, grain size reduction is primarily caused by mineral reactions and abundant nucleation of new grains. New plagioclase grains have a different composition from that of the original clasts (e.g., Fig. 7). The low defect densities, the narrow grain size range, and the lozengeshaped grains of the very fine-grained pure plagioclase aggregates within shear bands (Figs. 9-11) are in accordance with formation by nucleation and limited growth. Of the two initial mineral phases, plagioclase and pyroxene, plagioclase is particularly susceptible to grain size reduction via the reaction and nucleation of new grains. For all new phases, like zoisite and amphibole, it is clear that reaction and nucleation are the mechanisms leading to a small grain size and to phase mixing.

In the special case of the Ab+En experiment, it is difficult to observe an obvious change in the chemical composition of the plagioclase and to connect it to grain size reduction in shear bands. Qualitative EDX measurements reveal possible new pyroxene grains with higher $\mathrm{Si}$ and $\mathrm{Na}$ contents compared to the starting pyroxene. Due to the very small grain size, however, chemical measurements are challenging. No measurable change in plagioclase composition is detected but in order for the new pyroxene to grow with higher Si and $\mathrm{Na}$ contents compared to the starting material, a plagioclase with a higher anorthite component is expected to grow.

Microstructural evidence for grain size reduction by fracturing or the dynamic recrystallization (e.g., sub-grain ro- tation or bulging recrystallization) of plagioclase is not observed (see, e.g., Fig. 9). In addition, had the recrystallization of plagioclase in monomineralic domains taken place by dynamic recrystallization, the resulting grain sizes would imply very high stresses. Using the normalized grain size-stress relationship by Derby (1991), the observed plagioclase grain size mode of $\sim 0.4 \mu \mathrm{m}$ (Fig. 11) would require differential stresses of 2 to $2.5 \mathrm{GPa}$. The observed differential stresses are $\sim 500 \mathrm{MPa}$ in the last stages of this experiment (Fig. 2); they are clearly far too low to produce such a small grain size in equilibrium. As in other samples, the grain size reduction of plagioclase in the $\mathrm{Ab}+\mathrm{En}$ sample is considered to take place by the dissolution of original porphyroclasts and nucleation (i.e. "neo-crystallization") of new grains.

\subsection{Derivation of the stress exponent}

The determined $n$ values are low, with $n=1.4$ and 1.9 (Fig. 3), and are thus within the range of expected values for diffusion creep (including grain boundary sliding) with theoretical values between 1 (e.g., Ashby and Verrall, 1973; Coble, 1963; Karato, 2008; Kohlstedt and Hansen, 2015; Paterson, 2013) and 2 (e.g., Gratier et al., 2009, 2013; Paterson, 2013). The stress exponents determined in this study have to be taken with some caution as deformation of the samples is inhomogeneous. While the shear bands are able to accommodate higher strain rates, the lesser deformed domains in between seem to still control the overall bulk stress (Marti et al., 2017). Nevertheless, the low stress exponents strongly suggest an absence of frictional deformation and make dislocation creep unlikely.

\subsection{Dissolution-precipitation creep and grain boundary sliding}

From the mechanical data (including stress exponents), the determined grain sizes, and from the nucleation of new grains, it is concluded that in all samples the dominant deformation mechanism cannot be frictional or crystal plastic (dislocation creep). Instead, the dominant deformation mechanism is inferred to be DPC, accompanied and/or accommodated by mineral reactions. Pyroxene is less involved in accommodating strain but plays an important part by being involved in mineral reactions and thereby aiding grain size reduction by nucleation of new grains.

Mineral reactions change the initial phase assemblage of $\mathrm{Px}+\mathrm{Pl}$ to mostly $\mathrm{Pl}+\mathrm{Px}+\mathrm{Zo}$ in the synthetic mixtures and $\mathrm{Pl}+\mathrm{Px}+\mathrm{Amp}+\mathrm{Qz}+\mathrm{Zo}$ in Maryland diabase samples. Disregarding the differences in the amount and type of mineral reactions, strain is always localized into a network of shear bands characterized by intense grain size reduction and phase mixing (to a lesser extent in the Ab+En sample; Fig. 5).

The small size of grains in shear bands (Fig. 11) clearly favors a grain-size-sensitive deformation mechanism such as DPC and related grain boundary sliding. This interpretation 

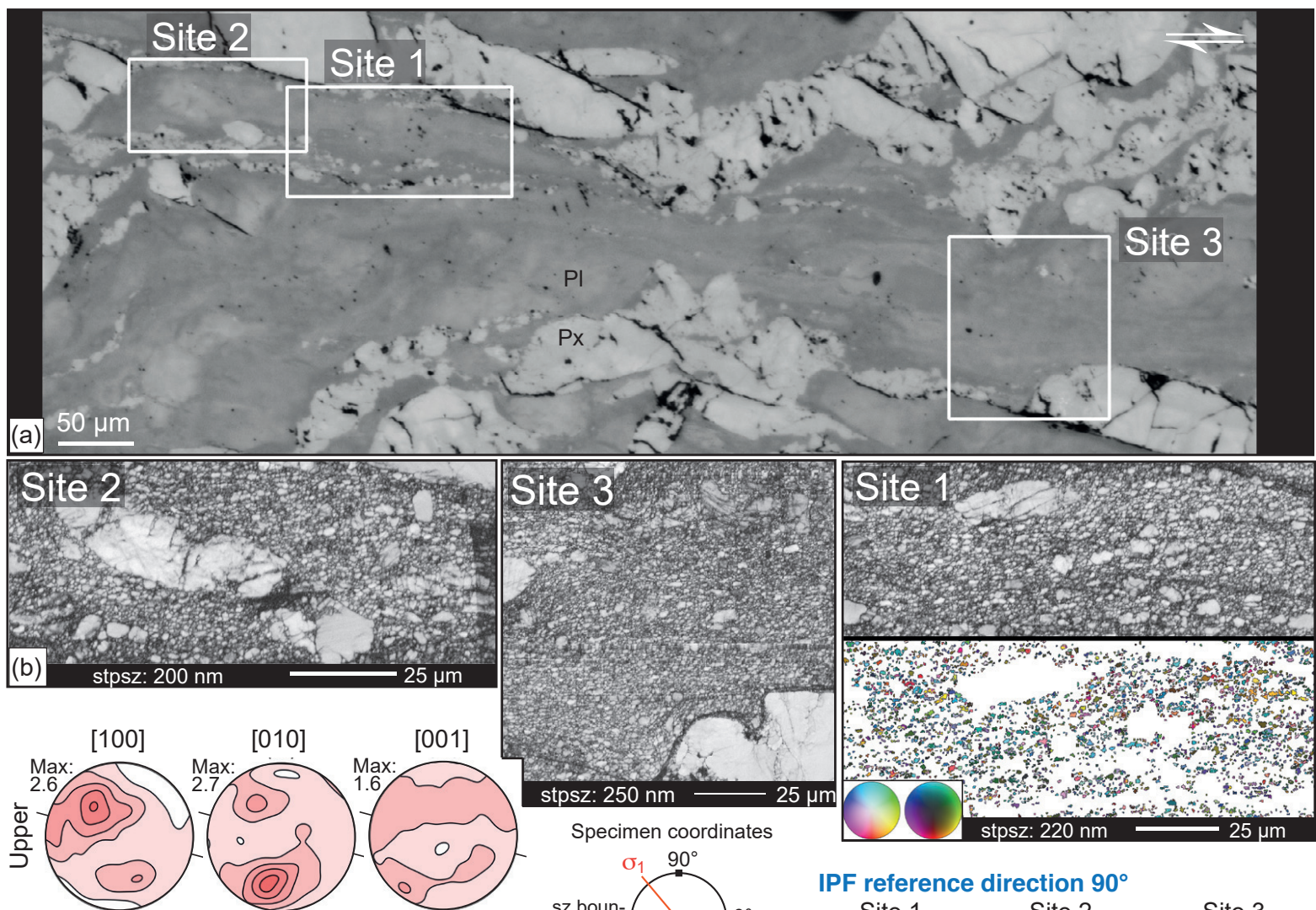

Specimen coordinates
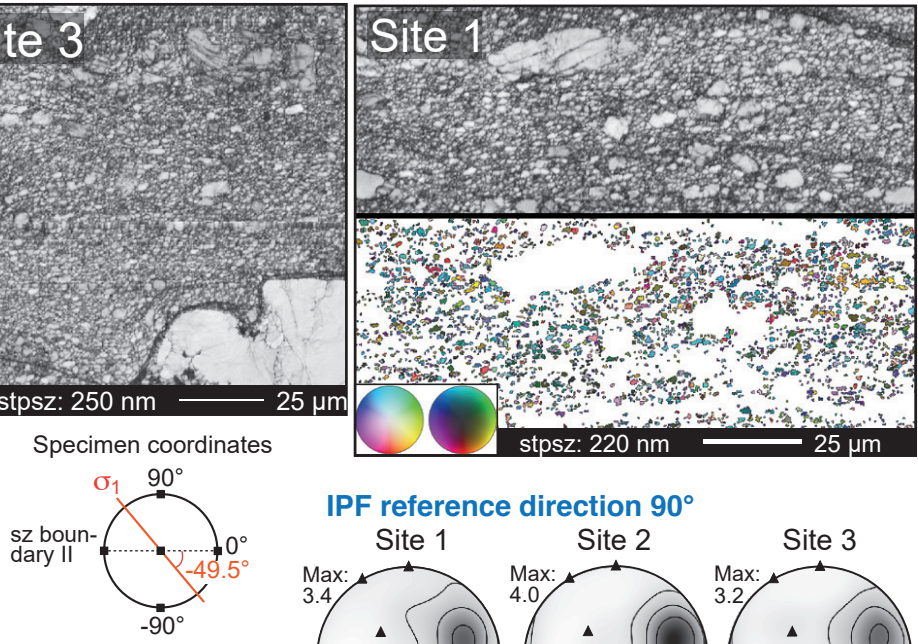
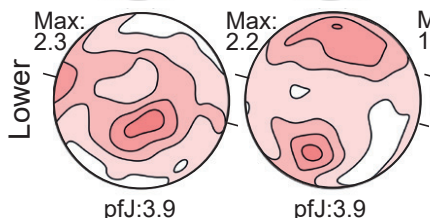

(010)

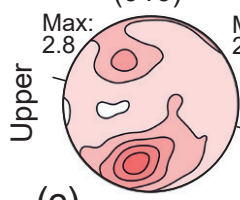

(c)

pfJ:3.9
(110)

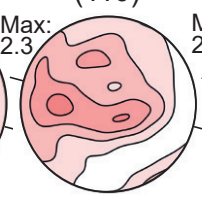

pfJ:3.9

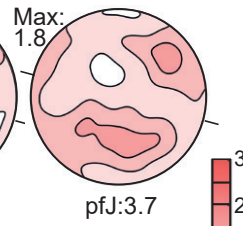

(110)

Crystal coordinates
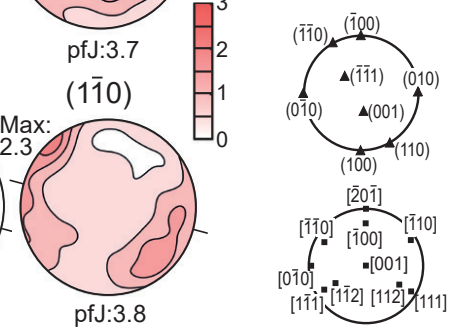

[111][1172] [1121]/111]

IPF reference direction $90^{\circ}$

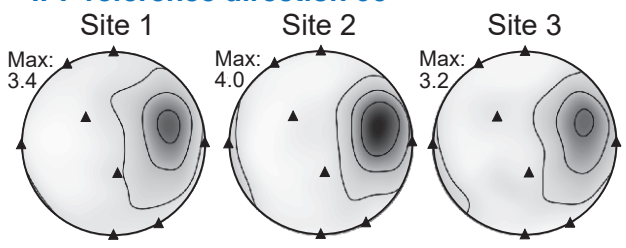

IPF reference direction $0^{\circ}$

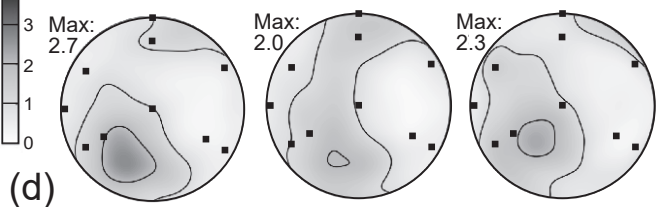

Figure 12. EBSD analysis of Ab+En sample. (a) Reflected light image. EBSD map locations are indicated; Pl: plagioclase, Px: pyroxene. (b) Band contrast images and EBSD map (for site 1, inverse pole figure coloring, $x$ direction); stpsz: step size. (c) Pole figures (equal area projections) plotted from combined data of all sites. Orientation data of grains $<2 \mu \mathrm{m}$ in diameter (and min. $>3$ pixels) are plotted. Small black lines at pole figure rims indicate approximate trace of shear band (plunging with $15^{\circ}$ to the right). (d) Inverse pole figures (IPFs) for directions and poles to planes, respectively, for reference directions 90 and $0^{\circ}$ (normal to the global shear plane and parallel to shear direction, respectively). For the specimen coordinate reference sketch, sz: shear zone. Number of grains analyzed: site 1: 2492, site 2: 1647, site 3: 3513 .

is also supported by the strain-free interior and grain morphology of the small grains in shear bands (Figs. 9 and 10). The activity of solution-mass transport processes is clearly indicated by the vast extent of mineral reactions, which necessitate the movement of chemical components over several tens of micrometers at least. The morphology of pores presented in Fig. 9 is further supporting evidence for DPC in- terpretation; the pore trail in Fig. 9d is interpreted to have formed by precipitation of plagioclase and entrapment of residual fluid along grain boundaries with a trace subparallel to the estimated $\sigma_{1}$ direction (expected opening direction of dilatancy normal to $\sigma_{1}$ ). 

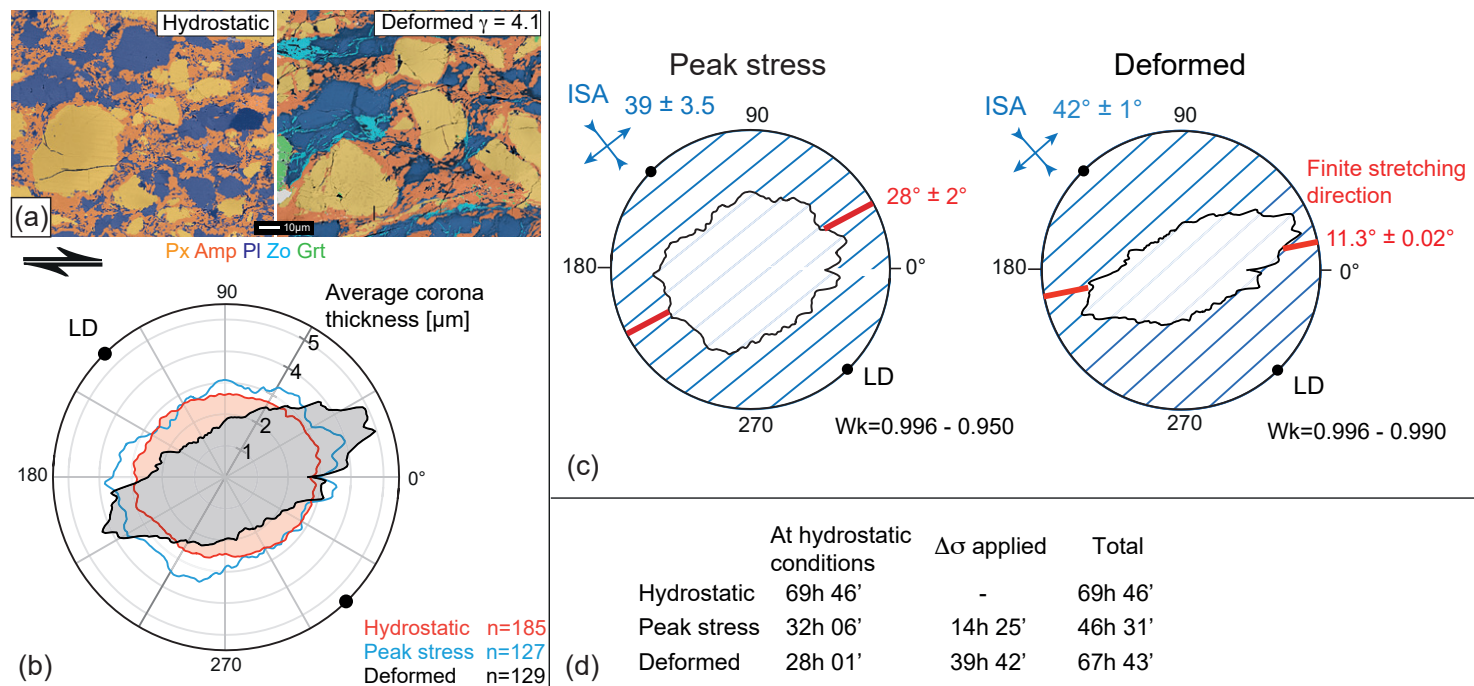

(c) Deformed $n=129$

(d)

$\begin{array}{lccr} & \begin{array}{c}\text { At hydrostatic } \\ \text { conditions }\end{array} & \Delta \sigma \text { applied } & \text { Total } \\ \text { Hydrostatic } & 69 \mathrm{~h} \mathrm{46}^{\prime} & - & 69 \mathrm{~h} \mathrm{46} \\ \text { Peak stress } & 32 \mathrm{~h} \mathrm{06} & 14 \mathrm{~h} \mathrm{25}{ }^{\prime} & 46 \mathrm{~h} \mathrm{31} \\ \text { Deformed } & 28 \mathrm{~h} \mathrm{01} & 39 \mathrm{~h} \mathrm{42} & 67 \mathrm{~h} \mathrm{43}\end{array}$

Figure 13. Analysis of amphibole coronas. Thickness of amphibole (Amp) corona on pyroxene (Px) porphyroclasts as a function of orientation from Maryland diabase experiments deformed at $\mathrm{Pc} \approx 1.5 \mathrm{GPa}$. (a) Phase map of microstructure developed when no $\Delta \sigma$ was applied ("hydrostatic") and in the case of sample deformation ( $\Delta \sigma>0$, "deformed"). (b) Average Amp corona thickness presented as a rose diagram; $n$ : number of analyzed coronas. Analysis for three different samples are presented:"hydrostatic", "peak stress" $\left(\gamma_{\mathrm{a}} \sim 0.6\right)$, and "deformed" $\left(\gamma_{\mathrm{a}} \sim 4\right)$. (c) Duration of experiments in hours $(\mathrm{h})$ and minutes $\left(^{\prime}\right)$. (d) Kinematic analysis of panel (b); blue lines indicate calculated instantaneous stretching directions. In red is the calculated finite stretching direction; LD: loading direction. Wk: kinematic vorticity number. The error range in the ISA direction, finite stretching direction, and Wk is caused by the uncertainty of the starting thickness of the shear zone.

\subsection{Evidence for dissolution-precipitation creep of amphibole}

Microstructural evidence for DPC is usually scarce but the truncation of grains (or other markers such as chemical zonation) and their overgrowths are sometimes correlated with deformation by DPC (e.g., Schwarz and Stöckhert, 1996; Wintsch and Yi, 2002; Svahnberg, 2010). The evolution of amphibole corona thicknesses has been analyzed to investigate if it could be explained in terms of amphibole deformation by DPC.

During the experiments, amphibole grows as a reaction product and pyroxene porphyroclasts are replaced at their rims by amphibole growth coronas. During all stages of an experiment, amphibole is observed to grow stably. Clasts with coronas are predominantly found in low strain lenses for which shear strains are lower than in shear bands. No microstructure can be found to indicate that the reduction in average corona thickness at the compressional sites of the clasts is due to "shearing-off" of amphibole from compressional to extensional sites by some sort of granular flow. On the contrary, the amphibole coronas, which grow symmetrically in thickness during the hydrostatic "lead run-in", become partly dissolved in high stress sites while simultaneously growing thicker in low stress sites during deformation (Fig. 13b). These results indicate grain-scale DPC of amphibole. It is frequently observed for amphiboles in naturally deformed rocks (e.g., Berger and Stünitz, 1996; Imon et al.,
2002; Marsh et al., 2009; Stokes et al., 2012), but has only rarely been reproduced in experimental studies (Rutter et al., 1985; Getsinger and Hirth, 2014).

The direction of the shortening ISA (equal to the direction of the instantaneous maximum principal stress, $\sigma_{1}$ ) lies within the range of directions of minimum average corona thickness. A correlation between the shortening ISA and the minimum in average corona thickness is consistent with the interpretation of DPC in which material is preferentially dissolved along high stress sites (and reprecipitated along low stress sites). During DPC, the grain shape change is determined by the stress field, whereby the instantaneous (i.e. for very low strains) shape change is expected to result in an orthorhombic grain shape with the short and long axis at $90^{\circ}$ and parallel to $\sigma_{1}$ and $\sigma_{3}$, respectively. With progressive deformation during DPC, grain boundary sliding will take place alongside, causing grain rotation and a deviation from this orthorhombic-shaped fabric. At the peak stress where shear strain is still small, the rim thickness shows an overall $\sim$ orthorhombic shape (see corona curve in Fig. 13c) well aligned with the ISAs. As the ISAs indicate the minimum and maximum principal stress directions, the fact that the corona curve follows the ISAs correlates well with the interpretation that DPC determines the amphibole corona thickness evolution. The monoclinic shape of the corona curve in the deformed case can be explained by a superposition of the coaxial geometry of deformation by diffusion creep and rigid 
body rotation induced by the rotational component of simple shear.

\subsection{Albite crystallographic preferred orientation}

Dislocation creep and dynamic recrystallization are not considered to occur in our experiments. The large Burgers vectors in plagioclase are unfavorable for intracrystalline deformation, especially at the comparatively low experimental temperatures of $800^{\circ} \mathrm{C}$. Dislocation glide and climb have been suggested to be active in plagioclase under both natural and experimental conditions (e.g., Tullis and Yund, 1985; Shaocheng and Mainprice, 1987; Yund and Tullis, 1991; Rybacki and Dresen, 2000; Shigmeatsu and Tanaka, 2000; Kruse et al., 2001; Lapworth et al., 2002; Stünitz et al., 2003; Ji et al., 2004; Barreiro et al., 2007; Mehl and Hirth, 2008) but usually are not considered to accommodate large amounts of strain. Recrystallization takes place by different mechanisms including neo-crystallization (e.g., Fitz Gerald and Stünitz, 1993; Rosenberg and Stünitz, 2003; Brander et al., 2012; Fukuda and Okudaira, 2013; Mukai et al., 2014) or by growth of fragments formed by fracturing (e.g., Stünitz et al., 2003; Viegas et al., 2016). In fine-grained aggregates, diffusion creep (in the broadest sense), often dissolutionprecipitation creep (DPC), is the main strain-accommodating process described for polycrystalline plagioclase aggregates (e.g., Yund and Tullis, 1991; Fitz Gerald and Stünitz, 1993; Jiang et al., 2000; Lapworth et al., 2002; Rosenberg and Stünitz, 2003; Brander et al., 2012; Fukuda and Okudaira, 2013; Mukai et al., 2014; Viegas et al., 2016).

The CPO measured in a shear band of the Ab+En sample 518 is generally weak, but the independent sites $1-3$ show very similar CPO patterns (Fig. 12c, d). This similarity indicates that these CPOs, although weak, are not random and that there must be a mechanism leading to this weak but systematic CPO.

There are a number of mechanisms that can lead to a CPO within an aggregate. Examples are dislocation glide (e.g., Schmid and Boas, 1950) or directed growth (possibly together with rigid body rotation; e.g., Shelley, 1994; Berger and Stünitz, 1996; Rosenberg and Stünitz, 2003; Getsinger and Hirth, 2014; Viegas et al., 2016). Furthermore, a CPO can form via host-controlled nucleation (e.g., Jiang et al., 2000) or caused by interface-controlled diffusion creep (e.g., Bons and den Brok, 2000; Sundberg and Cooper, 2008). Similar CPOs as the ones shown here have been found in experimentally deformed anorthite and basalt (e.g., Ji et al., 2004; Barreiro et al., 2007) and in naturally deformed basaltic and peridotitic rocks (e.g., Mehl and Hirth, 2008; Viegas et al., 2016; Xie et al., 2003; Drury et al., 2011). Ji et al. (2004) and Mehl and Hirth (2008) interpret the CPOs to be due to dislocation creep in monomineralic plagioclase layers. Viegas et al. (2016) observe no evidence for dislocation creep and suggest that the CPOs may be the result of directed growth and rigid body rotation of grains (with a crystallographically controlled grain shape) during diffusionaccommodated grain boundary sliding.

For plagioclase, the most commonly reported slip plane in dislocation glide is (010) (e.g., Kruse et al., 2001). However, although (010) aligns at a high angle to the shear plane (as seen from the pole figures, Fig. 12c), the position of the maxima in the IPF is significantly off $\left(\sim 35^{\circ}\right)$ the pole to $(010)$. Maxima in the IPF are close to [3-14] (for reference, direction is shear direction) and $(-121)$ (for reference, direction is normal to shear plane). They do not correlate with the [100] or [001] slip directions and the (010) slip plane commonly reported for feldspars in the literature. It is therefore argued that the CPO is not due to dislocation creep but rather caused by some other process(es) during grain-size-sensitive creep in the predominantly monomineralic albite layers.

The exact CPO-forming mechanism could not be determined. It may be speculated that the CPO formation could be due to directed and anisotropic growth during DPC and grain boundary sliding of grains with a crystallographically controlled shape. Studies on plagioclase crystal growth in magmatic environments usually determine [100] and/or [001] as fast growth directions and crystals forming with pronounced (010) planes (e.g., Smith, 1974). In hydrothermal growth experiments on albite, Franke and Ghobarkar (1982) report an increasing growth velocity of (110) at higher experimental temperatures (up to $\sim 700^{\circ} \mathrm{C}$ ). The alignment of (110) poles within the trace of the shear band (pole figures, Fig. 12c) and that of (010) poles at a high angle is conspicuous and may indicate that the CPO is caused by the combined mechanisms of grain rotation during deformation and anisotropic growth.

\subsection{Importance of dissolution-precipitation creep in natural rocks}

Grain size reduction is energetically unfavorable as it increases the total grain surface area. DPC does not necessarily require the formation of new grains; instead, precipitation could take place as overgrowth rims on existing grains. The intense grain size reduction observed in shear bands within our experiments is most probably caused by high nucleation rates. High nucleation rates are typically attained by a large overstepping of a reaction boundary (e.g., Rubie, 1998; Putnis, 1992), introducing a high driving potential. The start of our experiments represents such an instance of large overstepping of reaction boundaries. The starting materials $+\mathrm{H}_{2} \mathrm{O}$ are not in equilibrium at the experimental Pc$T$ conditions. As the pressurization and heating procedure required to attain the experimental Pc- $T$ conditions takes place within $5-8 \mathrm{~h}$, the sample material is brought rapidly to a metastable state. Although this rapid change in $P-T$ conditions is unique to experiments, there is widespread evidence from observations of natural rocks that, similarly, metastable mineral assemblages can be sustained even at high-grade conditions and to large overstepping of reaction boundaries when rocks are dry (e.g., Rubie, 1986; Austrheim, 1987; 
Wayte et al., 1989; Krabbendam et al., 2000; Austrheim, 2013; Jamtveit et al., 2016). Only where fluid infiltrates are mineral reactions enabled and equilibrium can be attained.

TEM analyses revealed high defect densities in the albite porphyroclasts (Fig. 9a, b). It has been proposed that a high intragranular defect density results in an increased rate of grain dissolution, speeding up the reaction and/or deformation rate (e.g., Wintsch, 1985; Schott et al., 1989; Stünitz, 1998). However, the observation of, e.g., abundant nucleation along former fractures (Fig. 5k) cannot simply be accredited to enhanced reaction rates due to locally increased strain energy (in the sense of high defect densities locally introduced by fracturing according to, e.g., Fitz Gerald et al., 1991; Fitz Gerald and Stünitz, 1993; Stünitz et al., 2003; Trepmann et al., 2007). Fracturing is always accompanied by dilatancy. Fluid infiltrates the fractures, leading to higher solution-mass transport rates (e.g., Fitz Gerald and Stünitz, 1993; Precigout and Stünitz, 2016). Thus higher reaction rates can be expected. The significance of strain energy as a possible rate-enhancing contributor to reaction and nucleation is thus difficult to separate from the effects of enhanced fluid flow.

With the dominant deformation mechanisms, DPC and grain boundary sliding, the samples presented here deform viscously. At the experimentally induced conditions of $T=$ $800^{\circ} \mathrm{C}$ and strain rates of $\sim 3 \times 10^{-5} \mathrm{~s}^{-1}$, deformation takes place at the lower end of the viscous field, close to the brittleviscous transition of the studied material (e.g., Marti et al., 2017). However, it is probable that the observed deformation mechanisms are also active at higher temperatures in these types of rocks. The principal constituent phases of mafic rocks (plagioclase + pyroxene + amphibole) all have high strengths in terms of intracrystalline plasticity, even at high temperatures. Where water is absent and DPC suppressed, the buildup of high stresses can be expected in such rocks, at least transiently (e.g., Okudaira et al., 2015). If local stresses are high enough to induce cracking, dilatancy and fluid infiltration may be facilitated. Once reactions start to operate (metastability of mafic rocks is very common because the mineral compositions are very variable and critically dependent on $P, T$, and fluid composition), a switch to DPC is likely to occur. The resulting deformation takes place with low stress exponents.

\subsection{Continued operation of deformation mechanisms at higher strain}

In the case of the experimental setup described here, in which the starting mineral assemblages are not in equilibrium at the imposed $P-T$ fluid conditions, the chemical driving potential for attaining a lower-energy assemblage partially controls the reaction rate (although for a stressed system, there is no unique driving force, i.e., Gibbs free energy, defined; e.g., Kamb, 1961; Wheeler, 2014, 2018). In principle, when the stable assemblage is reached, i.e., when the reaction has gone to completion, the driving potential for the dissolution of phases is reduced, and it may be expected that the deformation rate is reduced, too. Interestingly, the measured amphibole compositions show variations, which are most probably influenced by the local mineral composition of the other neighboring mineral phases (Fig. 8). Shear offset and neighbor switching during deformation by diffusion creep and grain boundary sliding will continuously change the local neighborhood of grains. As the neighborhood of a given grain changes, new surfaces will be brought into contact and become involved in reactions, potentially providing a relatively constant chemical driving force for reaction and nucleation if local disequilibrium prevails. Thus, it may take considerable time until the deforming assemblage has reached complete equilibrium, and some local chemical driving potentials may persist, even when the nominal bulk equilibrium assemblage has formed.

\section{Summary and conclusions}

i. Viscous deformation in experiments with mafic compositions at temperatures of $800^{\circ} \mathrm{C}$ and confining pressures of 1.0 and $1.5 \mathrm{GPa}$ at strain rates of $\sim 10^{-5} \mathrm{~s}^{-1}$ is dominantly achieved by dissolution-precipitation creep (DPC) and grain boundary sliding accompanied by syndeformational mineral reactions. No evidence for frictional deformation or significant contributions of dislocation glide or creep to the accommodation of strain can be found for any of the mineral phases. Strain is frequently localized into shear bands, which consist of fine-grained mixtures of neo-crystallized plagioclase and the syn-kinematic reaction products amphibole, quartz, and zoisite, none of which are present in the starting material.

ii. Intense grain size reduction is produced by high nucleation rates, probably caused by a large overstepping of reaction boundaries. Both deformation and nucleation are localized in shear bands, implying a positive feedback between the two mechanisms.

iii. Amphibole is seen to accommodate displacement via dissolution-precipitation creep, as interpreted from the evolution and distribution of amphibole coronas on pyroxene porphyroclasts.

iv. A weak but systematic crystallographic preferred orientation (CPO) of albite - unrelated to any known slips system operating in dislocation creep - is formed in the shear bands. The CPO is thereby interpreted to have developed as a result of deformation via DPC and grain boundary sliding.

v. The deformation in the samples takes place under conditions of pronounced weakening in all cases. The weakening is induced by strain localization into shear bands 
that show strong grain size reduction. Grain size reduction, in turn, is due to nucleation of new phases, demonstrating the direct relationship between mineral reaction, grain size refinement, and the operation of DPC and grain boundary sliding (as grain-size-sensitive mechanisms), resulting in viscous deformation with low stress exponents.
Code and data availability. The MATLAB code for analyzing amphibole reaction corona thicknesses is available from the author upon request (sina.marti@ed.ac.uk). Mechanical data and chemical analyses are available from the author upon request. 


\section{Appendix A: Methods}

\section{A1 Sample preparation}

Maryland diabase rock powder is fabricated by crushing Maryland diabase pieces with a handpress and subsequently with an alumina hand mortar. The resulting powder is drysieved to extract a grain size fraction $\leq 125 \mu \mathrm{m}$. The plagioclase in Maryland diabase shows a relatively homogeneous composition ( $\sim$ An65-70) except for a thin rim with lower anorthite component ( $\sim$ An50-55). The core to rim area ratio is $83: 17( \pm 3)$. Some of the clinopyroxene grains show a $\mathrm{Mg}$-enriched core and clinopyroxene grains generally show orthopyroxene exsolution lamellae.

The diopside and enstatite material is a mineral powder provided by Jacques Precigout (University d'Orléans) and Holger Stünitz (University of Troms $\varnothing$, University d'Orléans) with grain sizes of 40-125 $\mu \mathrm{m}$ for Cranberry Lake diopside and 40-180 $\mu \mathrm{m}$ for Damaping enstatite. Damaping enstatite and diopside are derived from a peridotite xenolith and the Cranberry Lake diopside from a calc-silicate rock. The albite material is extracted from an albite-quartz vein formed along a joint from the Alpe Rischuna area, Switzerland. Sonora labradorite consists of labradorite megacrysts formed in basaltic deposits from the Pinacate volcanic field, Sonora, Mexico. From Sonora labradorite, Alpe Rischuna albite, and Damaping diopside a powder (grain size fraction $\leq 125 \mu \mathrm{m}$ ) is produced in the same manner as described for the Maryland diabase powder. As the Sonora labradorite material shows some accessory calcite, the powder is cleaned with $\mathrm{HCl}_{\mathrm{aq}}(10 \%)$. Subsequently, the powder is placed in a funnel with a grade $602 \mathrm{~h}$ qualitative filter paper with a pore size of $2 \mu \mathrm{m}$ and rinsed thoroughly with distilled water. The powder retained by the filter is then dried in an oven at $\sim 110^{\circ} \mathrm{C}$. After this treatment, no calcite is detected in the material.

Synthetic plagioclase-pyroxene powders are mixed with a phase distribution of $\sim 57 \%$ vol plagioclase to $43 \%$ vol pyroxene. To produce the synthetic mixtures, the powders are placed in a $5 \mathrm{~mL}$ glass beaker with acetone and mixed using an ultrasonic stirrer (procedure of de Ronde et al., 2004). When most of the acetone is evaporated, the slurry is dried in an oven at $110^{\circ} \mathrm{C}$. This procedure prevents grain size and density sorting of the minerals.

The sample is then placed in a platinum jacket $(0.15 \mathrm{~mm}$ wall thickness) with a $0.025 \mathrm{~mm}$ nickel foil insert. The Pt jacket is weld-sealed with a Lampert welding apparatus while the sample is encased in a cooled brass piece $(T \sim$ $4^{\circ} \mathrm{C}$ ) to minimize sample heating and resulting potential water loss.

Solid sodium chloride $(\mathrm{NaCl})$ is used as a confining medium (Appendix Fig. A1a). K-type thermocouples (with metal tubing) positioned next to the sample are used for most experiments. Only for long-duration experiments of more than 6 days are S-type thermocouples (with mullite tubing) used, as the mullite tubing is more durable in the corrosive environment of the heated salt.

\section{A2 Experimental procedure}

Confining pressure, axial load, and displacement are constantly recorded. The force on the load piston is measured using an external load cell, whereas the displacement of the load piston is measured with either a direct-current displacement transducer (resolution $\sim 1 \mu \mathrm{m}$ ) (Rig 1) or a noiseless digital linear-transformation measurement system (resolution $0.1 \mu \mathrm{m}$ ) (Rig 2). Pc is measured via the oil pressure in the hydraulic pumping system and $T$ is monitored and regulated to within $\pm 1{ }^{\circ} \mathrm{C}$ via a Eurotherm controller.

To bring the sample to the desired Pc- $T$ conditions during pressurization, the independently movable Pc and load pistons are alternately advanced (thereby raising the pressure), accompanied by stepwise increases in temperature until the desired Pc- $T$ conditions are reached (Fig. 2). The pressurization procedure usually takes $5-8 \mathrm{~h}$. During the actual deformation experiment, only the load piston is advanced. The experimental setup necessitates that each deformation experiment starts with a so-called "lead run-in", whereby the load piston is advanced through a thin $(\sim 1.5 \mathrm{~mm})$ top lead layer. During this stage, the sample is expected to experience approximate isotropic pressure. During the initial lead run-in, the sample is under approximate hydrostatic conditions for several hours (usually between 24-30 h). Once the hit point is reached, sample loading initiates. At the end of an experiment, the sample is quenched to $200^{\circ} \mathrm{C}$ within $2 \mathrm{~min}$ while simultaneously removing the differential load. Subsequently, Pc, load, and $T$ are slowly and simultaneously reduced to room conditions within about $5 \mathrm{~h}$.

\section{A3 Evaluation of mechanical data}

Axial displacement is corrected for apparatus stiffness. $\sigma_{3}$ is assumed to be equal to the confining pressure, Pc (Eq. A1). With increasing advancement of the load piston, the pressure inside the vessel increases and $\mathrm{Pc}$ is corrected for this (see e.g., Richter et al., 2016). The differential stress, $\Delta \sigma$, acting on the sample is derived from the difference between the axial load $(F)$ with reference to the load at the hit point $\left(F_{0}\right)$ (Eq. A2) and the cross-sectional area of the forcing block $\left(31.47 \mathrm{~mm}^{2}\right)$.

$\sigma_{3}=\mathrm{Pc}$

$\Delta \sigma=\left(F-F_{0}\right) / 31.47 \mathrm{~mm}^{2}$

$\Delta \sigma$ in the sample is corrected for the decreasing overlap of the forcing blocks (see procedure described in Marti et al., 2017). The shear and normal stresses, $\tau$ and $\sigma_{n}$, supported by the sample inclined at $45^{\circ}$ are obtained by Mohr circle construction from $\Delta \sigma$. The effective pore fluid pressures in our experiments are assumed to be negligible, i.e. are taken 
(a)

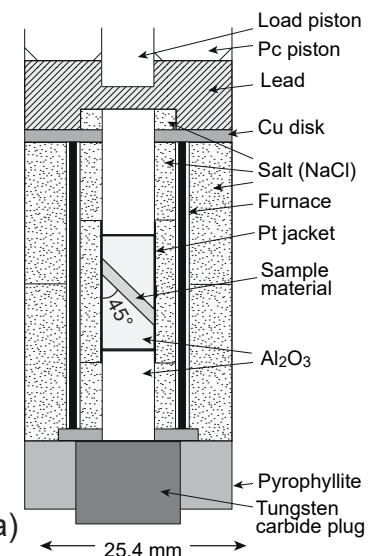

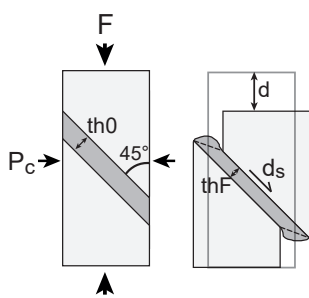

(b)

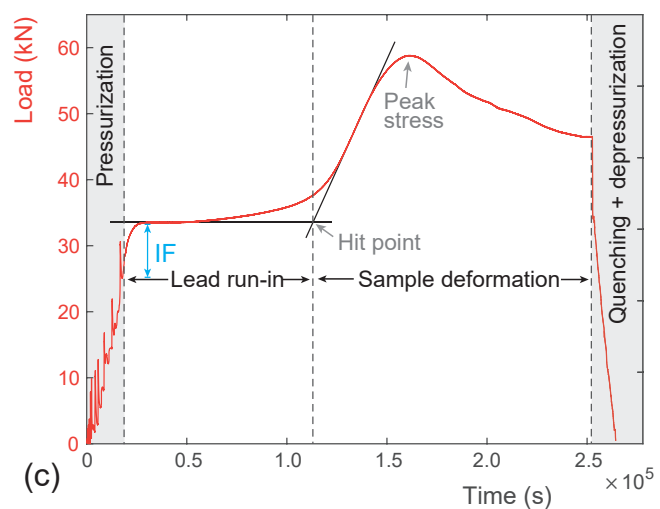

Figure A1. General shear experiments. (a) Sample assembly in cross section. (b) Schematic sample cross section at the start of experiment (left) and after sample deformation (right). $F$ : load induced by load piston, Pc: confining pressure, $d$ : axial displacement, ds: shear displacement, th0: shear zone thickness at start, thF: shear zone thickness at end of experiment. (c) Phases of an experiment; red line: load $F(t)$. During "pressurization", the sample is brought to the desired Pc- $T$ conditions. Black dot denotes the start of experiment. IF: initial load increase caused by machine friction. Phase 1: "lead run-in"; the sample is not loaded. Phase 2: sample supports load and deforms. "Hit point" denotes the onset of sample loading. During "quenching + depressurization", the load is released and the temperature brought to ambient conditions.

as zero and the deviation of $\sigma_{1}$ by $3-6^{\circ}$ from $45^{\circ}$ is neglected as well.

The stress exponent, $n$, is calculated for a relationship

$\tau=\dot{\gamma}_{\mathrm{a}}^{1 / n}$

between shear stress, $\tau$, and strain rate, $\dot{\gamma}_{\mathrm{a}}$ (Eq. A3), using data of displacement rate stepping and single-displacementrate experiments.

Over the years and between the different laboratories, different data treatment routines have been developed and are in use. The variations in calculated stresses using the different methods can influence the determined stress exponents $(n)$ from the data, causing variations of the order of $16-27 \%$ in determined $n$ values (see Marti et al., 2017)

\section{A4 Strain and flow descriptors}

The ISA and the finite stretching direction can be derived because the initial thickness of the shear zone is known (with an error of $\pm 0.03 \mathrm{~mm}$ ) and the end thickness can be measured after the experiment from the thin section. This uncertainty associated with the initial thickness leads to some uncertainty concerning the amount of thinning and therefore also to a range of values for the ISA, the finite stretching direction, and $\mathrm{Wk}$.

\section{A5 Microstructure analysis}

\section{A5.1 Data acquisition}

SEM analyses are performed either with the Zeiss Merlin SEM at Troms $\varnothing$ University or with a Philips XL30 ESEM at the nano-imaging lab of the Swiss Nanoscience Institute (SNI) at Basel University. Chemical analyses are performed using standardless energy-dispersive X-ray spectrometry (EDS) at $15 \mathrm{keV}$ of acceleration voltage with a ZAF matrix correction for spectra quantification.

Scanning transmission electron microscopy (STEM) analyses are performed at Utrecht University using a FEI Talos 200FX equipped with a high-sensitivity Super-EDX system. TEM images are recorded in bright-field (BF) mode, whereas STEM images are in high-angular annular dark-field (HAADF) mode. BF-TEM images are highly sensitive to crystallographic orientation, whereas contrasts in HAADFSTEM images are sensitive to the average atomic number ( $\mathrm{Z}$ contrast) of the material. Focused ion beam (FIB) foils for TEM investigations are prepared using an FEI Helios NanoLab G3. The FIB foils are cut parallel to the shear direction and normal to the shear plane. Both the FEI Talos 200FX and the NanoLab G3 are located at the electron microscopy square at Utrecht University.

\section{A5.2 EBSD analysis}

For electron backscatter diffraction (EBSD) measurements, thin sections were polished with colloidal silica suspension and subsequently coated with a thin layer of carbon. Samples were analyzed in the Zeiss Merlin SEM at the University of Troms $\varnothing$ with a Nordlys nano-camera in high vacuum at $15 \mathrm{keV}$ of acceleration voltage and probe currents of $\sim 15 \mathrm{nA}$. Data are acquired with the Oxford AZtec software and processed with Channel 5 and the MATLAB toolbox MTEX (available at https://mtex-toolbox.github.io, last access: January 2018; Bachmann et al., 2010). Orientation 
data are analyzed and plotted using MTEX. The de la Vallée Poussin kernel with a half-width of $10^{\circ}$ was used for pole figure contouring, whereas a kernel half-width of $12^{\circ}$ was used for contouring of inverse pole figures (IPFs). All pole figures and IPFs are calculated with Laue symmetry. Pole figure J index (PFJ; e.g., Bunge, 1982; Mainprice and Silver, 1993) values are given as a measure of texture strength. The index has a value of 1 for a random distribution and is infinite for a single orientation.

\section{A5.3 Image analysis}

Phase segmentation is performed on BSE-SEM images, whereby individual minerals are identified by their $\mathrm{Z}$ contrast. Using the software Fiji (link at: http://fiji.sc/Fiji; last access: August 2017) and the plugin Statistical Region Merger, automatic pre-segmentation was achieved. The automatic segmentation was then manually inspected and corrected where necessary.
Grain maps were produced by manually tracing (supervised segmentation) grains from SEM or TEM images. Grains were analyzed for their 2-D area using Fiji, and for each grain the diameter of the area equivalent circle, $d_{\text {equ }}$, is calculated.

$d_{\mathrm{equ}}=2 \cdot \sqrt{(A / \pi)}$

$A$ is the area of the digitized shape. Grain size distributions are presented as histograms of the 2-D number-weighted distribution of equivalent diameters.

Shear bands are traced and digitized on BSE-SEM images. The $x-y$ coordinates of the outlines of the digitized structures are smoothed to remove pixel artifacts and exported using Fiji. The smoothed $x-y$ coordinates are used as input for the SURFOR program (Panozzo Heilbronner, 1984; Heilbronner and Barrett, 2014), which determines the orientation distribution function (ODF) of the boundary segments. The ODFs are presented as rose diagrams. 


\section{The Supplement related to this article is available online at https://doi.org/10.5194/se-9-985-2018-supplement.}

Competing interests. The authors declare that they have no conflict of interest.

Acknowledgements. We thank the team of the center for nanoimaging (SNI) at the University of Basel and Tom Eilertsen at Troms $\varnothing$ University for help and assistance with the electron microscopy. Terry Tullis is thanked for providing the Maryland diabase material, and the Cranberry Lake diopside was kindly provided by Jacques Précigout. Willy Tschudin is thanked for excellent thin section preparation. We gratefully acknowledge the funding provided by the Swiss National Foundation grant NF 200020_144448 and financial support from the Freiwillige Akademische Gesellschaft, Basel, during the last stages of finishing this paper. John Wheeler and Andrew Cross are thanked for thorough reviews and their suggestions and comments to improve the paper.

Edited by: Michael Heap

Reviewed by: John Wheeler and Andrew Cross

\section{References}

Ashby, M. F. and Verrall, R. A.: Diffusion-accommodated Flow and Superplasticity, Acta Metall. Mater., 21, 149-163, 1973.

Austrheim, H.: Eclogitization of lower crustal granulites by fluid migration through shear zones, Earth Planet. Sc. Lett., 81, 221232, 1987.

Austrheim, H.: Fluid and deformation induced metamorphic processes around Moho beneath continent collision zones: Examples from the exposed root zone of the Caledonian mountain belt, W-Norway, Tectonophysics, 609, 620-635, 2013.

Bachmann, F., Hielscher, R., and Schaeben, H.: Texture Analysis with MTEX - Free and Open Source Software Toolbox, Sol. St. Phen., 160, 63-68, 2010.

Barreiro, J. G., Lonardelli, I., Wenk, H., Dresen, G., Rybacki, E., Ren, Y., and Tome, C.: Preferred orientation of anorthite deformed experimentally in Newtonian creep, Earth Planet. Sc. Lett., 264, 188-207, 2007.

Berger, A. and Herwegh, M.: Grain coarsening in contact metamorphic carbonates: effects of second-phase particles, fluid flow and thermal pertubations, J. Metamorph. Geol., 22, 459-474, 2004.

Berger, A. and Stünitz, H.: Deformation mechanisms and reaction of hornblende: examples from the Bergell tonalite (Central Alps), Tectonophysics, 257, 149-174, 1996.

Bons, P. D. and den Brok, B.: Crystallographic preferred orientation development by dissolution-precipitation creep, J. Struct. Geol., 22, 1713-1722, 2000.

Brander, L., Svahnberg, H., and Piazolo, S.: Brittle-plastic deformation in initially dry rocks at fluid-present conditions: transient behaviour of feldspar at mid-crustal levels, Contrib. Mineral. Petr., 163, 403-425, 2012.
Brodie, K. H. and Rutter, E. H.: The role of transiently fine-grained reaction prodcuts in syntectonic metamorphism: natural and experimental examples, Can. J. Earth Sci., 24, 556-564, 1987.

Bunge, H. J.: Texture Analysis in Materials Sciences, Buttleworth, London, UK, 1982.

Bürgmann, R. and Dresen, G.: Rheology of the Lower Crust and Upper Mantle: Evidence from Rock Mechanics, Geodesy, and Field Observations, Annu. Rev. Earth Pl. Sc., 36, 531-567, 2008.

Burov, E. B.: Rheology and strength of the lithosphere, Mar. Petrol. Geol., 28, 1402-1443, 2011.

Bystricky, M. and Mackwell, S.: Creep of dry clinopyroxene aggregates, J. Geophys. Res., 106, 13443-13454, 2001.

Chen, S., Hiraga, T., and Kohlstedt, D. L.: Water weakening of clinopyroxene in the dislocation creep regime, J. Geophys. Res., 111, B08203, https://doi.org/10.1029/2005JB003885, 2006.

Coble, R. L.: A Model for Boundary Diffusion Controlled Creep in Polycrystalline Materials, J. Appl. Phys., 34, 1679-1682, 1963.

Cross, A. J. and Skemer, P.: Ultramylonite generation via phase mixing in high-strain experiments, J. Geophys. Res.-Sol. Ea., 122, 1744-1759, 2017.

Derby, B.: The dependence of grain size on stress during dynamic recrystallisation, Acta Metall. Mater., 39, 955-962, 1991.

de Ronde, A. A., Heilbronner, R., Stünitz, H., and Tullis, J.: Spatial correlation of deformation and mineral reaction in experimentally deformed plagioclase-olivine aggregates, Tectonophysics, 389, 93-109, 2004.

de Ronde, A. A., Stünitz, H., Tullis, J., and Heilbronner, R.: Reaction-induced weakening of plagioclase-olivine composites, Tectonophysics, 409, 85-106, 2005.

Dimanov, A. and Dresen, G.: Rheology of synthetic anorthite-diopside aggregates: Implications for ductile shear zones, J. Geophys. Res., 110, B07203, https://doi.org/10.1029/2004JB003431, 2005.

Dimanov, A., Dresen, G., Xiao, X., and Wirth, R.: Grain boundary diffusion creep of synthetic anorthite aggregates: The effect of water, J. Geophys. Res., 104, 10483-10497, 1999.

Dimanov, A., Lavie, M. P., Dresen, G., Ingrin, J., and Jaoul, O.: Creep of polycrystalline anorthite and diopside, J. Geophys. Res., 108, B001815, https://doi.org/10.1029/2002JB001815, 2003.

Dimanov, A. E., Rybacki, E., Wirth, R., and Dresen, G.: Creep and strain-dependent microstructures of synthetic anorthite-diopside aggre-gates, J. Struct. Geol., 29, 1049-1069, 2007.

Drury, M., Avé Lallemant, H., Pennock, G., and Palasse, L.: Crystal preferred orientation in peridotite ultramylonites deformed by grain size sensitive creep, Étang de Lers, Pyrenees, France, J. Struct. Geol., 33, 1776-1789, 2011.

Etheridge, M. A. and Wilkie, J. C.: Grainsize reduction, grain boundary sliding and the flow strength of mylonites, Tectonophysics, 58, 159-178, 1979.

Fitz Gerald, J. D. and Stünitz, H.: Deformation of Granitoids at low Metamorphic Grade. 1. Reactions and Grain-size Reduction, Tectonophysics, 221, 269-297, 1993.

Fitz Gerald, J. D., Boland, J. N., McLaren, A. C., Ord, A., and Hobbs, B.: Microstructures in water-weakened single crystals of quartz, J. Geophys. Res.-Sol. Ea., 96, 2139-2155, 1991.

Fossen, H. and Tikoff, B.: The deformation matrix for simultaneous simple shearing, pure shearing and volume change, and its ap- 
plication to transpression-transtension tectonics, J. Struct. Geol., 15, 413-422, 1993.

Franke, W. and Ghobarkar, H.: The Morphology of Hydrothermally grown Plagioclase, Cryst. Res. Technol., 17, 459-464, 1982.

Fukuda, J.-I. and Okudaira, T.: Grain-size-sensitive Creep of Plagioclase accompanied by Solution-Precipitation and Mass Transfer under Mid-crustal Conditions, J. Struct. Geol., 51, 61-73, 2013.

Getsinger, A. J. and Hirth, G.: Amphibole fabric formation during diffusion creep and the rheology of shear zones, Geology, 42, 535-538, 2014.

Gratier, J.-P., Guiget, R., Renard, F., Jenatton, L., and Bernard, D.: A pressure solution creep law for quartz from indentation experiments, J. Geophys. Res., 114, B03403, https://doi.org/10.1029/2008JB005652, 2009.

Gratier, J.-P., Dysthe, D. K., and Francois, R.: The role of pressure solution creep in the ductility of the Earth's upper crust, Adv. Geophys., 54, 47-179, 2013.

Handy, M. R. and Stünitz, H.: Strain localization by fracturing and reaction weakening - a mechanism for initiating exhumation of subcontinental mantle beneath rifted margins, Geol. Soc. Lon., Spec. Pub., 200, 387-407, 2002.

Hawthorne, F., Oberti, R., Harlow, G., Maresch, W., Martin, R., Schumacher, J., and Welch, M.: Nomenclature of the amphibole supergroup, Am. Mineral., 97, 2031-2048, 2012.

Heilbronner, R. and Barrett, S.: Image Analysis in Earth Sciences - Microstructures and Textures of Earth Materials, SpringerVerlag, Berlin, Germany, 2014.

Hickman, S. H. and Evans, B.: Experimental pressure solution in halite: the effect of grain/interphase boundary structure, J. Geol. Soc. London, 148, 549-560, 1991.

Hier-Majumder, S., Mei, S., and Kohlstedt, D. L.: Water weakening of clinopyroxenite in diffusin creep, J. Geophys. Res., 110, B07406, https://doi.org/10.1029/2004JB003414, 2005.

Imon, R., Okudaira, T., and Fujimoto, A.: Dissolution and precipitation processes in deformed amphibolites: an example from the ductile shear zone of the Ryoke metamorphic belt, SW Japan, J. Metamorph. Geol., 20, 297-308, 2002.

Jamtveit, B., Austrheim, H., and Putnis, A.: Disequilibrium metamorphism of stressed lithosphere, Earth-Sci. Rev., 154, 1-13, 2016.

Ji, S., Jiang, Z., Rybacki, E., Wirth, R., Prior, D. J., and Xia, B.: Strain softening and microstructural evolution of anorthite aggregates and quartz-anorthite layered composites deformed in torsion, Earth Planet. Sc. Lett., 222, 377-390, 2004.

Jiang, Z., Prior, D. J., and Wheeler, J.: Albite crystallographic preferred orientation and grain misorientation distribution in a lowgrade mylonite: implications for granular flow, J. Struct. Geol., 22, 1663-1674, 2000.

Kamb, W. B.: The thermodynamic theory of nonhydrostatically stressed solid, J. Geophys. Res., 66, 259-271, 1961.

Karato, S.-I.: Deformation of Earth Materials - an introduction to the rheology of solid earth, Cambridge University Press, Cambridge, UK, 2008.

Kilian, R., Heilbronner, R., and Stünitz, H.: Quartz grain size reduction in a granitoid rock and the transition from dislocation to diffusion creep, J. Struct. Geol., 33, 1265-1284, 2011.
Kohlstedt, D. L. and Hansen, L. N.: Constitutive equations, rheological behavior, and viscosity of rocks, in: Treatise on Geophysics, edited by: Schubert, G., Elsevier, Oxford, UK, 441-472, 2015.

Kohlstedt, D. L., Evans, B., and Mackwell, S. J.: Strength of the Litosphere: Constraints imposed by laboratory experimetns, J. Geophys. Res.-Sol. Ea., 100, 517-587, https://doi.org/10.1029/95JB01460, 1995.

Kolle, J. J. and Blacic, J. D.: Deformation of Single-Crystal Clinopyroxenes: Mechanical Twinning in Diopside and Hedenbergite, J. Geophys. Res., 87, 4019-4034, 1982.

Krabbendam, M., Wain, A., and Andersen, T. B.: Pre-Caledonian granulite and gabbro enclaves in the Western Gneiss Region, Norway: indications of incomplete transition at high pressure, Geol. Mag., 137, 235-255, 2000.

Kronenberg, A. K. and Shelton, G. L.: Deformation microstructures in experimentally deformed Maryland Diabase, J. Struct. Geol., 2, 341-353, 1980.

Kruse, R. and Stünitz, H.: Deformation mechanisms and phase distribution in mafic high-temperature mylonites from the Jotun Nappe, southern Norway, Tectonophysics, 303, 223-249, 1999.

Kruse, R., Stünitz, H., and Kunze, K.: Dynamic recrystallization processes in plagioclase porphyroclasts, J. Struct. Geol., 23, 1781-1802, 2001.

Lallemant, H. A.: Experimental Deformation of Diopside and Websterite, Tectonophysics, 48, 1-27, 1978.

Langdon, T. G.: Grain boundary sliding revisited: Developments in sliding over four decades, J. Mater. Sci., 41, 597-609, 2006.

Lapworth, T., Wheeler, J., and Prior, D. J.: The Deformation of Plagioclase investigated using Electron Backscatter Diffraction Crystallographic Preferred Orientation Data, J. Struct. Geol., 24, 387-399, 2002.

Linckens, J., Herwegh, M., Müntener, O., and Mercolli, I.: Evolution of a polymineralic mantle shear zone and the role of second phases in the localization of deformation, J. Geophys. Res., 116, B06210, https://doi.org/10.1029/2010JB008119, 2011.

Linckens, J., Bruijn, R. H., and Skemer, P.: Dynamic recrystallization and phase mixing in experimentally deformed peridotite, Earth Planet. Sc. Lett., 388, 134-142, 2014.

Mainprice, D. and Silver, P. G.: Interpretation of SKS-waves using samples from the subcontinental lithosphere, Phys. Earth Planet. In., 78, 257-280, 1993.

Marsh, J., Johnson, S., Yates, M., and West, J.: Coupling of deformation and reactions during mid-crustal shear zone development: an in situ frictional-viscous transition, J. Metamorph. Geol., 27, 531-553, 2009.

Marti, S., Stünitz, H., Heilbronner, R., Plümper, O., and Drury, M.: Experimental investigation of the brittle-viscous transition in mafic rocks - Interplay between fracturing, reaction, and viscous deformation, J. Struct. Geol., 105, 62-79, 2017.

Mauler, A., Bystricky, M., Kunze, K., and Mackwell, S.: Microstructures and lattice preferred orientations in experimentally deformed clinopyroxene aggregates, J. Struct. Geol., 22, 16331648, 2000.

Mehl, L. and Hirth, G.: Plagioclase preferred orientation in layered mylonites: Evaluation of flow laws for the lower crust, J. Geophys. Res.-Sol. Ea., 113, B05202, https://doi.org/10.1029/2007JB005075, 2008.

Mukai, H., Austrheim, H., Putnis, C. V., and Putnis, A.: Textural Evolution of Plagioclase Feldspar across a Shear Zone: Implica- 
tions for Deformation Mechanism and Rock Strength, J. Petrol., 55, 1457-1477, 2014.

Newman, J., Lamb, W. M., Drury, M. R., and Vissers, R. L. M.: Deformation processes in a peridotite shear zone: reaction-softening by an $\mathrm{H}_{2} \mathrm{O}$-deficient, continuous net transfer reaction, Tectonophysics, 303, 193-222, 1999.

Okudaira, T., Jerabek, P., H., S., and Fusseis, F.: High-temperature fracturing and subsequent grain-size-sensitive creep in lower crustal gabbros: Evidence for coseismic loading followed by creep during decaying stress in the lower crust?, J. Geophys. Res.-Sol. Ea., 120, 3119-3141, 2015.

Olgaard, D. L. and Evans, B.: Effect of Second-Phase Particles on Grain Growth in Calcite, J. Am. Ceram. Soc., 69, 272-277, 1986.

Panozzo Heilbronner, R.: Two-dimensional strain from the orientation of lines in a plane, J. Struct. Geol., 6, 215-221, 1984.

Paterson, M. S.: Superplasticity in Geological Materials, Mat. Res. Soc. Symp. Proc., 196, 1341-1358, 1990.

Paterson, M. S.: A theory for granular flow accommodated by material transfer via an intergranular fluid, Tectonophysics, 245, 135151,1995

Paterson, M. S.: Materials Science for Structural Geology, Springer, Dordrecht, the Netherlands, 2013.

Precigout, J. and Stünitz, H.: Evidence of phase nucleation during olivine diffusion creep: A new perspective for mantle strain localisation, Earth Planet. Sc. Lett., 455, 94-105, 2016.

Putnis, A.: Introduction to mineral sciences, Cambridge University Press, New York, USA, 1992.

Raterron, P. and Jaoul, O.: High-temperature deformation of diopside single crystal, 1. Mechanical data, J. Geophys. Res., 96, 14277-14286, 1991.

Richter, B., Stünitz, H., and Heilbronner, R.: Stresses and pressures at the quartz-to-coesite phase transformation in sheardeformation experiments, J. Geophys. Res.-Sol. Ea., 121, JB013084, https://doi.org/10.1002/2016JB013084, 2016.

Rosenberg, C. L. and Stünitz, H.: Deformation and recrystallization of plagioclase along a temperature gradient: an example from the Bergell tonalite, J. Struct. Geol., 25, 389-408, 2003.

Rubie, D. C.: The catalysis of mineral reaction by water and restrictions of the presence of aqueous fluid during metamorphism, Mineral. Mag., 50, 399-415, 1986.

Rubie, D. C.: Disequilibrium during metamorphism: the role of nucleation kinetics, Geol. Soc. SP, 138, 199-214, 1998.

Rutter, E. H., Peach, C. J., White, S. H., and Johnston, D.: Experimental "syntectonic" hydration of basalt, J. Struct. Geol., 7, 251266, 1985.

Rybacki, E. and Dresen, G.: Dislocation and diffusion creep of synthetic anorthithe aggregates, J. Geophys. Res.-Sol. Ea., 105, 26017-26036, 2000.

Schmid, E. and Boas, W.: Plasticity of Crystals with Special Reference to Metals, F.A. Hughes, London, UK, 1950.

Schott, J., Brantley, S., Crerar, D., Guy, C., Borcsik, M., and Willaime, C.: Dissolution kinetics of strained calcite, Geochem. Cosmochim. Ac., 53, 373-382, 1989.

Schwarz, S. and Stöckhert, B.: Pressure solution in siliciclastic HPLT metamorphic rocks - constraints on the state of stress in deep levels of accretionary complexes, Tectonophysics, 255, 203-209, 1996.

Shaocheng, J. and Bin, X.: Rheology of polyphase earth materials, Polytechnic International Press, Montreal, Canada, 2002.
Shaocheng, J. and Mainprice, D.: Experimental deformation of sintered albite above and below the ordered-disorder transition, Geodin. Acta, 1, 113-124, 1987.

Shelley, E.: Spider texture and amphibole preferred orientations, J. Struct. Geol., 16, 709-717, 1994.

Shigmeatsu, N. and Tanaka, H.: Dislocation creep of fine-grained recrystallized plagioclase under low-temperature conditions, J. Struct. Geol., 22, 65-79, 2000.

Smith, J. V.: Feldspar Minerals, vol. 2, Springer, Berlin, Germany, 1974.

Stokes, M., Wintsch, R., and Southworth, C.: Deformation of amphibolites via dissolution-precipitation creep in the middle and lower crust, J. Metamorph. Geol., 30, 723-737, 2012.

Stünitz, H.: Syndeformational recrystallization - dynamic or compositionally induced?, Contrib. Mineral. Petr., 131, 219-236, 1998.

Stünitz, H. and Tullis, J.: Weakening and strain localization produced by syn-deformational reaction of plagioclase, Int. J. Earth Sci., 90, 136-148, 2001.

Stünitz, H., Fitz Gerald, J. D., and Tullis, J.: Dislocation generation, slip systems, and dynamic recrystallization in experimentally deformed plagioclase single crystals, Tectonophysics, 372, 215-233, 2003.

Sundberg, M. and Cooper, R. F.: Crystallographic preferred orientation produced by diffusional creep of harzburgite: Effects of chemical interactions among phases during plastic flow, J. Geophys. Res., 113, B12208, https://doi.org/10.1029/2008JB005618, 2008.

Svahnberg, H.: Deformation behaviour and chemical signatures of anorthosites: Examples from southern West Greenland and south-central Sweden, PhD thesis, Stockholm University, Stockholm, Sweden, 2010.

Tikoff, B.: The limitations of three-dimensional kinematic vorticity analysis, J. Struct. Geol., 17, 1771-1784, 1995.

Trepmann, C. A., Stöckert, B., Dorner, D., Moghadam, R. H., Küster, M., and Röller, K.: Simulating coseismic deformation of quartz in the middle crust and fabric evolution during postseismic stress relaxation - An experimental study, Tectonopyhsics, 442, 83-104, 2007.

Tullis, J. and Yund, A.: Dynamic recrystallization of feldspar: A mechanism for ductile shear zone formation, Geology, 13, 238241, 1985.

Tullis, J. and Yund, A.: Diffusion creep in feldspar aggregates: experimental evidence, J. Struct. Geol., 13, 987-1000, 1991.

Viegas, G., Menegon, L., and Archanjo, C.: Brittle grain-size reduction of feldspar, phase mixing and strain localization in granitoids at mid-crustal conditions (Pernambuco shear zone, NE Brazil), Solid Earth, 7, 375-396, https://doi.org/10.5194/se-7-375-2016, 2016.

Wayte, G. J., Worden, R. H., Rubie, D. C., and Droop, G. T. R.: A TEM study of disequilibrium plagioclase breakdown at high pressure: the role of infiltrating fluid, Contrib. Mineral. Petr., 101, 426-437, 1989.

Wheeler, J.: Importance of Pressure Solution and Coble Creep in the Deformation of Polymineralic Rocks, J. Geophys. Res., 97, 4579-4586, 1992.

Wheeler, J.: Dramatic effects of stress on metamorphic reactions, Geology, 42, 647-650, 2014. 
Wheeler, J.: The effects of stress on reactions in the Earth: sometimes rather mean, usually normal, always important, J. Metamorph. Geol., 36, 439-461, 2018.

Whitney, D. and Evans, B. W.: Abbrevations for names of rockforming minerals, Am. Mineral., 95, 185-187, 2010.

Wintsch, R. P.: The Possible Effects of Deformation on Chemical Processes in Metamorphic Fault Zones, in: Advances in Physical Geochemistry, 4, Springer-Verlag, New York, USA, 1985.

Wintsch, R. P. and Yi, K.: Dissolution and replacement creep: a significant deformation mechanism in mid-crustal rocks, J. Struct. Geol., 24, 1179-1193, 2002.
Xie, Y., Wenk, H.-R., and Matthies, S.: Plagioclase preferred orientation by TOF neutron diffraction and SEM-EBSD, Tectonophysics, 370, 269-286, 2003.

Yund, R. A. and Tullis, J.: Compositional change of minerals associated with dynamic recrystallization, Contrib. Mineral. Petr., 108, 346-355, 1991.

Zhang, J., Green, H. W., and Bozhilov, K. N.: Rheology of omphacite at high temperature and pressure and significance of its lattice preferred orientations, Earth Planet. Sc. Lett., 246, 432443, 2006. 